\title{
Article \\ Why Is the Correct Selection of Trichoderma Strains Important? The Case of Wheat Endophytic Strains of T. harzianum and T. simmonsii
}

\author{
Alberto Pedrero-Méndez (D), H. Camilo Insuasti, Theodora Neagu, María Illescas, M. Belén Rubio (D), \\ Enrique Monte $(\mathbb{D}$ and Rosa Hermosa *D \\ Institute for Agribiotechnology Research (CIALE), Department of Microbiology and Genetics, \\ University of Salamanca, Campus de Villamayor, C/Duero, 12, 37185 Salamanca, Spain; \\ alberto.pedrerom@usal.es (A.P.-M.); hcinsuastia@usal.es (H.C.I.); theodora@usal.es (T.N.); \\ millesmor@usal.es (M.I.); belenru@usal.es (M.B.R.); emv@usal.es (E.M.) \\ * Correspondence: rhp@usal.es
}

check for

updates

Citation: Pedrero-Méndez, A.; Insuasti, H.C.; Neagu, T.; Illescas, M.; Rubio, M.B.; Monte, E.; Hermosa, R. Why Is the Correct Selection of Trichoderma Strains Important? The Case of Wheat Endophytic Strains of T. harzianum and T. simmonsii. J. Fungi 2021, 7, 1087. https://doi.org/ $10.3390 /$ jof7121087

Academic Editor: Susanne Zeilinger

Received: 22 October 2021

Accepted: 16 December 2021

Published: 17 December 2021

Publisher's Note: MDPI stays neutral with regard to jurisdictional claims in published maps and institutional affiliations.

Copyright: (c) 2021 by the authors. Licensee MDPI, Basel, Switzerland. This article is an open access article distributed under the terms and conditions of the Creative Commons Attribution (CC BY) license (https:/ / creativecommons.org/licenses/by/ $4.0 /)$.

\begin{abstract}
The search for endophytic fungi in the roots of healthy wheat plants from a non-irrigation field trial allowed us to select 4 out of a total of 54 cultivable isolates belonging to the genus Trichoderma, identified as T. harzianum T136 and T139, T. simmonsii T137, and T. afroharzianum T138. In vitro assays against the phytopathogenic fungus Fusarium graminearum showed that the T. harzianum strains had the highest biocontrol potential and that T136 exhibited the highest cellulase and chitinase activities. Production patterns of eight phytohormones varied among the Trichoderma strains. All four, when applied alone or in combination, colonized roots of other wheat cultivars and promoted seed germination, tillering, and plant growth under optimal irrigation conditions in the greenhouse. Apart from T136, the endophytic Trichoderma strains showed plant protection capacity against drought as they activated the antioxidant enzyme machinery of the wheat plants. However, T. simmonsii T137 gave the best plant size and spike weight performance in water-stressed plants at the end of the crop. This trait correlated with significantly increased production of indole acetic acid and abscisic acid and increased 1-aminocyclopropane-1-carboxylic acid deaminase activity by T137. This study shows the potential of Trichoderma endophytes and that their success in agricultural systems requires careful selection of suitable strains.
\end{abstract}

Keywords: T. afroharzianum; biological control agent (BCA); Fusarium graminearum; ACC deaminase; fungal phytohormones; IAA; ABA; ROS; antioxidant activity; drought tolerance

\section{Introduction}

Endophytic fungi are important components of the microbiota living in healthy plant tissues without causing them obvious symptoms. They are increasingly being studied due to their ability to assist the plant in its defense against both biotic and abiotic stresses [1]. Trichoderma species are common soil residents and most strains have demonstrated the ability to colonize the rhizosphere and to establish symbiotic relationships with plants [2,3], becoming endophytes [4,5]. Some Trichoderma species are even recognized as obligate endophytic biotrophs [6].

Trichoderma is the most widely used genus of fungi in biological control. There are almost 400 species of Trichoderma [7], and more than a dozen have strains in commercial use as they are, themselves, active matter for biocontrol or are used as a biological solution for plant disease control [8-10]. Amongst the most used Trichoderma-based biological control agents (BCA) are strains of the species T. atroviride, T. asperellum, and T. harzianum [11-14]. The taxonomy of T. harzianum has been particularly controversial for many years $[15,16]$ and new species with high biocontrol interest have been split off from this species aggregate $[17,18]$. As a BCA, Trichoderma can suppress pathogens through 
the production of hydrolytic enzymes such as glucanases; chitinases; and proteases (parasitism); secretion of toxic compounds, including volatiles (antibiosis); and competition for a specific niche (nutrients, plant tissues, etc.) $[6,13,19,20]$. This behavior is much more complex than it seems at first glance, since a given strain often synchronously uses several mechanisms or even displays different mechanisms against different pathogens [21,22]. Trichoderma can also exert an indirect biocontrol action through the plant by inducing systemic defenses $[10,13,23]$. In addition to modulating the plant's signaling network, mediated by phytohormones [24-26], Trichoderma strains can produce their own phytohormones, such as auxins, gibberellins (GA), cytokinins (CK), salicylic acid (SA), and abscisic acid (ABA), which increase the complexity of the Trichoderma-plant interactions and affect processes such as colonization, host plant growth, and the activation of defenses in stressful situations $[21,24,27-30]$. Trichoderma can also affect plant phytohormone production and networking by the secretion of enzymes that can modify plant ethylene (ET) levels, such as 1-aminocyclopropane-1-carboxylic acid (ACC) deaminase (ACCD) [31].

Wheat is one of the most important crops to humankind with a global production volume of over 772 million metric tons in 2020/2021 [32]. By 2050, as consequence of increasing population growth, feed grain demand is anticipated to reach 880 million metric tons. These crop yields can be affected by pathogen attacks. Fusarium graminearum $(F g)$ is a major causative agent of cereal Fusarium head blight disease [33] since it causes yield losses that are derived from reduction of grain size, weight, and germination rates, because of accumulation of mycotoxins in the grains [34]. Trichoderma gamsii T6085 has been shown to be effective in reducing wheat colonization and mycotoxin production by $F g$ [35]. Wheat cultivation is also globally affected by water shortages with drought being recognized as an important constraint for wheat production [36]. In addition, wheat is one of the field crops that is most dependent on the application of chemical inputs of both fungicides and fertilizers [37-39]. It is evident that the restrictions of the use of agrochemicals and the social demand for sustainable and less polluting agriculture make Trichoderma a viable and acceptable alternative.

Reactive oxygen species (ROS) are constantly generated at basal levels by plants as unwanted byproducts of aerobic metabolism. They do not cause damage because ROS are continuously scavenged by the plant's antioxidant machinery [40]. The delicate balance between ROS generation and ROS scavenging can be disturbed by stress factors such as salinity, extreme temperatures, and drought. ROS serve as damage markers in plants but they also act as triggers for stress signaling to prevent further damage $[10,41]$. As an effective rhizosphere colonizer, Trichoderma tolerates the ROS in the root environment [42], while at the same time it can activate the plant's antioxidant machinery to scavenge ROS. This Trichoderma trait, together with ACCD production, has proven to be effective in protecting wheat plants against abiotic stresses [30,43,44]. Early studies in cocoa described how Trichoderma favors the production of plant metabolites that are associated with increased drought tolerance $[4,45]$.

In this study, we obtained 54 isolates from the endosphere of Triticum aestivum of the Berdun variety that were assigned at the genus level. The four that belonged to Trichoderma were molecularly identified at the species level. Our aim was to determine whether the phylogenetically very close Trichoderma endophytic isolates showed similar biocontrol potential and/or beneficial effects on wheat plants to select them for the most efficient application. To achieve this goal, the four Trichoderma strains were included in further assays to analyze their: (i) biocontrol potential against $F g$ through different mechanisms, (ii) phytohormone production profiles, (iii) ACCD activity, (iv) capacity for root colonization of other wheat varieties in single or combined strain applications, (v) effects on wheat emergence and plant growth promotion, and (vi) ability to alleviate drought stress in wheat plants. 


\section{Materials and Methods}

\subsection{Isolation of Fungal Endophytes from Wheat Roots}

Fungal strains were isolated from the roots of healthy seven-month-old wheat plants (Triticum aestivum Berdun $\mathrm{R}$ variety) from a field assay. Once the soil that was attached to the roots was removed, $3.5 \mathrm{~g}$ of root system was collected, cut into segments of $1 \mathrm{~cm}$, and washed by shaking at $180 \mathrm{rpm}$ for $20 \mathrm{~min}$, as previously described [39]: twice in $20 \mathrm{~mL}$ PBS-S buffer (130 mM NaCl, $7 \mathrm{mM} \mathrm{Na}_{2} \mathrm{HPO}_{4}, 3 \mathrm{mM} \mathrm{NaH} \mathrm{PO}_{4}, \mathrm{pH} 7.0,0.02 \%$ Silwet L-77); once in $35 \mathrm{~mL}$ of $2 \%$ commercial sodium hypochlorite; and three times in $35 \mathrm{~mL}$ of PBS buffer. Subsequently, the roots were transferred to a tube with $35 \mathrm{~mL}$ PSB buffer, sonicated at $40 \mathrm{kHz}$ for $20 \mathrm{~min}$, and washed in $35 \mathrm{~mL}$ PBS buffer. The segments were placed horizontally onto potato dextrose agar (PDA; Difco Laboratories, Detroit, MI, USA) that was supplemented with $300 \mathrm{mg} / \mathrm{L}$ chloramphenicol (six pieces per $8.5 \mathrm{~cm}$ diameter plate). The Petri plates were incubated at $25^{\circ} \mathrm{C}$ in the dark for four days to allow fungal emergence from the edges of the wheat root fragments. A PDA plug was taken from the edge of each emerged fungal colony and separately plated onto PDA to isolate endophytes. The pathogen Fusarium graminearum $(F g)$ was provided by the Centro Regional de Diagnóstico de Salamanca (Aldearrubia, Salamanca, Spain). The fungi were routinely grown on PDA medium.

\section{Assay of Fungal Drought Tolerance}

A total of 54 fungal isolates were tested for resistance to different concentrations of polyethylene glycol 6000 (PEG; Sigma-Aldrich Química S.A., Madrid, Spain). A conidial suspension (200 conidia in $10 \mu \mathrm{L}$ ) of the fungus was used to inoculate each well of sterile 96well flat-bottomed microtiter plates containing $100 \mu \mathrm{L}$ of potato dextrose broth (PDB; Difco Laboratories, Detroit, MI, USA), with 0, 10, 20, 30, or 40\% (vol/vol) PEG. The microtiter plates were incubated at $28{ }^{\circ} \mathrm{C}$ and $20 \mathrm{rpm}$ in the dark for 7 days. For each fungus, an assay was performed using four replicates and the growth results were expressed using the following scale: - (no growth), + to +++ (increasing hyphal growth), and ++++ (completely bushy well).

\subsection{Fungal Molecular Identification}

The total fungal DNA was extracted following the method of Raeder and Broda [46] using mycelium that was collected from a cellophane sheet that was deposited on the surface of a PDA plate, where the fungus was grown at $28^{\circ} \mathrm{C}$ for $48 \mathrm{~h}$. The ITS1-ITS4 region of the nuclear rDNA gene cluster, including ITS1 and ITS2 and the 5.8S rDNA gene, was amplified with the primer pair ITS1/ /ITS4 for the 54 fungal isolates, as previously described [17]. In addition, a fragment of the tef1 $\alpha$ gene and one fragment of the acl1 gene were respectively amplified with the primer pairs EF1-728F (5'-CATCGAGAAGTTCGAGAAGG-3')/ / tef1rev (5'-GCCATCCTTGGAGACCAGC-3') and acl1-230up (5'-AGCCCGATCAGCTCATCAAG$\left.3^{\prime}\right) / /$ acl1-1220low (5'-CCTGGCAGCAAGATCVAGGAAGT-3') for the four Trichoderma isolates, as previously described $[47,48]$. The PCR products were electrophoresed on $1 \%$ agarose gels. The amplicons were excised from the gels, purified, and sequenced as previously described $[17,30]$. The sequences that were obtained were analyzed considering homology in the NCBI database, with ex-type strains and taxonomically established isolates of Trichoderma as references.

\subsection{Antifungal Assays of Trichoderma Strains against Fg}

\subsubsection{Dual Culture}

A total of two sets of dual culture assays were performed. The first was the classical confrontation assay between the Trichoderma strains T136, T137, T138, and T139, and the isolate of $F g$, which were carried out as previously described [49]. The cultures of the pathogen and the Trichoderma strains growing alone were used as controls. The colony area of $F g$ was measured after 4 days incubation at $28^{\circ} \mathrm{C}$ in the dark, and photographs were taken. Dual cultures were performed in quadruplicate and the results were expressed 
as the Fg colony growth inhibition percentage. A second assay was used to evaluate the antibiotic activity of volatile organic compounds (VOC) that were produced by Trichoderma against Fg. The effects of VOC that was produced by the strains T136, T137, T138, and T139 were tested towards $F g$ mycelial growth in centrally partitioned (biocompartment) $8.5 \mathrm{~cm}$ Petri plates. A $5 \mathrm{~mm}$ diameter $\mathrm{Fg}$ mycelium plug was placed at the center of one side of the partition plates containing PDA, and a $5 \mathrm{~mm}$ diameter Trichoderma mycelium plug was placed at the center of the other partition containing PDA. Fg plates without Trichoderma inoculum were used as a control. The inoculated plates were sealed with parafilm and incubated at $28^{\circ} \mathrm{C}$. The experiments were conducted four times and photographs were taken after $72 \mathrm{~h}$.

\subsubsection{Growth Membrane Assays}

Growth assays on the cellophane sheets and $12.5 \mathrm{kDa}$ cut-off dialysis cellulose membranes were carried out as previously described [49], with some modifications. Trichoderma strains were previously grown at $28^{\circ} \mathrm{C}$ for $36 \mathrm{~h}$ and the diameters of the $\mathrm{Fg}$ colony were measured after $72 \mathrm{~h}$ of incubation at $28{ }^{\circ} \mathrm{C}$ in the dark. The results are expressed as the percentage of $F g$ growth inhibition by each Trichoderma strain tested, T136, T137, T138, and T139, with respect to the mean colony diameters of $F g$ grown alone. Each strain and condition were tested in quadruplicate.

\subsubsection{Extracellular Hydrolytic Activities}

A Trichoderma conidial suspension $\left(10^{5}\right.$ conidia/mL) was used to inoculate $250 \mathrm{~mL} \mathrm{Er}$ lenmeyer flasks containing $120 \mathrm{~mL}$ of a synthetic medium (SM) [50] that was supplemented with $2 \%(\mathrm{wt} / \mathrm{vol})$ glucose $(\mathrm{SM}+2 \% \mathrm{Glu})$ or $0.5 \%(\mathrm{wt} / \mathrm{vol})$ cell walls of $\mathrm{Fg}(\mathrm{SM}+0.5 \%$ $\mathrm{Fg}$-CWs), which were incubated in a rotary shaker at $150 \mathrm{rpm}$ and $28^{\circ} \mathrm{C}$ for 5 days. Fg-CWs were obtained as previously described [51]. Each strain and culture medium were tested in triplicate. The resulting supernatants were collected in a Buchner funnel and then were 100-fold concentrated by ammonium sulfate precipitation and dialyzed against distillate water for $72 \mathrm{~h}$. Quantitative protein determination was performed by a Bradford assay [52] with bovine serum albumin as a protein standard. Protease, cellulase, and chitinase activities were determined in colorimetric assays, as previously described [53], by measuring the release of azo dye during hydrolysis of azocasein at $366 \mathrm{~nm}$, the release of reducing groups during the hydrolysis of carboxymethylcellulose at $520 \mathrm{~nm}$, and the release of $\mathrm{N}$-acetylglucosamine during hydrolysis of chitin at $585 \mathrm{~nm}$, respectively. Measurements were also performed in triplicate. The total activity corresponded to micromoles that were formed in one minute and specific activities corresponded to micromoles in one minute per milligram of protein.

\subsection{ACCD Activity}

The ACCD activity of the T136, T137, T138, and T139 strains was tested as previously described [30]. Briefly, $100 \mu \mathrm{L}$ of a conidial suspension $\left(1 \times 10^{6}\right.$ conidia $\left./ \mathrm{mL}\right)$ was inoculated in $10 \mathrm{~mL}$ of SM [50], and the cultures were grown at $180 \mathrm{rpm}$ and $28^{\circ} \mathrm{C}$ for 4 days. The mycelia were collected and homogenized in $2.5 \mathrm{~mL}$ Tris buffer $0.1 \mathrm{M}(\mathrm{pH}$ 8.5). The protein concentration in the samples was calculated as described above. The reaction mixture was prepared by adding $25 \mu \mathrm{L}$ of toluene and $20 \mu \mathrm{L}$ of $0.5 \mathrm{M}$ ACC to a protein aliquot of $200 \mu \mathrm{L}$. ACCD activity was determined in a colorimetric assay by measuring the amount of $\alpha$-ketobutyrate that was produced by the deamination of ACC at $540 \mathrm{~nm}$. A standard curve that was prepared with $\alpha$-ketobutyrate $(10-200 \mu \mathrm{mol})$ was used as reference. ACCD activity corresponded to millimoles of $\alpha$-ketobutyrate that were formed in $1 \mathrm{~h}$, and specific ACCD activity corresponded to millimoles of $\alpha$-ketobutyrate in $1 \mathrm{~h}$ per milligram of protein. A total of three independent cultures were analyzed for each strain, and activity measurements were also performed in triplicate. 


\subsection{Phytohormone Production by Trichoderma Strains}

The strains T136, T137, T138, and T139 were grown in $120 \mathrm{~mL}$ of PDB and PDB with $200 \mathrm{mg} / \mathrm{L}$ of tryptophan (PDB-Trp) media at $180 \mathrm{rpm}$ and $28^{\circ} \mathrm{C}$ for $48 \mathrm{~h}$, and the culture supernatants were collected by filtration in a Buchner funnel. Uninoculated PDB and PDBTrp media were used as their respective controls. The supernatants were lyophilized and the dry weight was measured. A quantity of $50 \mathrm{mg}$ of lyophilized supernatant was used for hormone extraction, as previously described [54]. The production of eight phytohormones [IAA, ABA, cytokinin dihydrozeatin (DHZ), cytokinin isopentenyladenine (iP), cytokinin trans-zeatin (tZ), SA, gibberellin $1\left(\mathrm{GA}_{1}\right)$, and gibberellin $4\left(\mathrm{GA}_{4}\right)$ ] by the four Trichoderma strains was determined as previously described [30]. A total of three independent replicate flasks were analyzed for each strain and culture medium.

\subsection{Colonization of Wheat Roots by Trichoderma Strains}

The quantification of Trichoderma DNA in wheat roots was performed by quantitative PCR (qPCR), as previously described [30]. The following six conditions were tested: control (uninoculated), T136, T137, T138, T139, and a mixture of these four Trichoderma strains. Briefly, three 10-day-old wheat seedlings that were grown in $8 \mathrm{~mL}$ of Murashige and Skoog (MS; Duchefa Biochemie BV, Haarlem, The Netherlands) medium plus 1\% sucrose were inoculated with $8 \times 10^{5}$ conidial germlings of Trichoderma, that was obtained and counted as previously described [55]. The roots were collected $48 \mathrm{~h}$ after inoculation of Trichoderma germlings or not (control), washed with sterile water, homogenized under liquid nitrogen, and used for DNA extraction. qPCR was performed in a Step One Plus thermocycler (Applied Biosystems, Foster City, CA, USA), using KAPA SYBR FAST (Biosystems, Buenos Aires, Argentine) and the previously described primer couples Act-F ( $5^{\prime}$ ATCGGTATGGGTCAGAAGGA-3')//Act-R (5'-ATGTCAACACGAGCAATGG-3') [56] and Act-Fw (5'-TGACCGTATGAGCAAGGAG-3')// Act-Rv (5'-CCAGACACTGTACTTCCTC$\left.3^{\prime}\right)$ [26] to amplify a fragment of the actin gene from Trichoderma and wheat. The reaction mixtures were made in triplicate, and the PCR conditions and DNA estimation using Ct values and standard curves were as previously described [21]. DNA that was extracted from four independent fungus-plant cultures per condition was tested.

The quantification of Trichoderma strains was also carried out by counting the number of colony-forming units (cfu) from one root (ca. $0.25 \mathrm{~g}$ ) of each wheat plant. For this, the roots were sampled on the wheat plants of the greenhouse assay described below at 21 days after sowing. Each sampled root was washed twice in $20 \mathrm{~mL}$ PBS-S buffer by shaking at $180 \mathrm{rpm}$ in a $50 \mathrm{~mL}$ tube for $20 \mathrm{~min}$. Serial dilutions of the rhizosphere washing liquid were plated on Trichoderma selective medium (TSM) [57]. The plates were incubated at $28^{\circ} \mathrm{C}$ and the cfu were counted after six days. In addition, the colonies of the Mix treatment that grew on TSM were then separately plated on PDA for subsequent morphological distinction and Trichoderma species assignment. One root of the four wheat plants per treatment was tested.

\subsection{Trichoderma-Wheat Assay under Greenhouse Conditions}

The effect of Trichoderma strains T136, T137, T138, and T139, that was applied alone or combined in a mixture on wheat growth promotion or drought stress alleviation was tested in a greenhouse assay. Wheat (Basilio variety) seeds were surface disinfected and seed stratification was performed as previously described [30]. The plant growth substrate consisted of an autoclaved mixture of commercial peat and vermiculite in a 3:1 proportion (Projar Professional, Comercial Projar SA, Fuente el Saz de Jarama, Spain). Trichoderma mycelium was applied to the plant growth substrate that was contained in conical pots of $250 \mathrm{~mL}$ capacity. Mycelium was obtained from a PDB culture, using $0.5 \mathrm{~L}$ flasks containing $250 \mathrm{~mL}$ of PDB inoculated with $1 \times 10^{6}$ conidia/mL, and grown at $180 \mathrm{rpm}$ and $28^{\circ} \mathrm{C}$ for 6 days. The mycelium was collected by filtration, washed with sterile water, and used to inoculate the plant growth substrate. This assay included six initial treatments and a total of 192 plants ( 2 plants per pot and 32 plants per treatment), named as follows: uninoculated (control), T136, T137, T138, T139, and Mix. Mycelium that was obtained from $250 \mathrm{~mL}$ of 
PDB was used for inoculation of the 16 pots of each treatment, except for treatment Mix, in which one quarter of each mycelium from each Trichoderma strain was mixed and the mixture served to inoculate the substrate that was contained in 16 pots. The plants were maintained in a greenhouse at $22 \pm 4{ }^{\circ} \mathrm{C}$, as previously described [25], and watered as needed for 3 weeks. The plants of each treatment that are described above were separated into two blocks: (i) 16 plants per treatment were maintained with optimal irrigation (control irrigation condition), and (ii) 16 plants per treatment were maintained without watering for 2.5 weeks (water stress condition). Then, all plants were watered as needed for 15.5 more weeks. A scheme with the running and sampling time points of this experiment is shown in Figure 1. The experiment lasted 21 weeks.

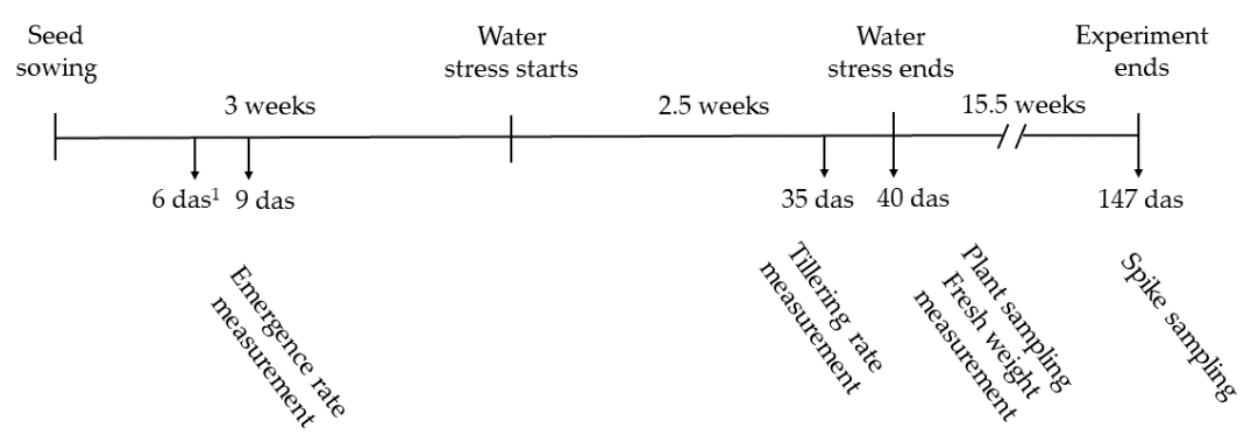

Figure 1. Representation of the running and sampling time points for the wheat-Trichoderma assay performed under greenhouse conditions. ${ }^{1}$ das: days after sowing.

\subsection{Physiological Measurements in Wheat Plants}

The plant emergence rate was determined at 6 and 9 days, and the results were expressed in percentage. Tillering data were taken on 35-day-old wheat plants (eight plants per treatment and condition). The total shoots of wheat plants were collected at 40 days to determine the fresh weight (four plants per treatment and condition). The plant height and spike weight were recorded on 21-week-old plants (four plants per treatment and condition).

\subsection{Determination of $\mathrm{H}_{2} \mathrm{O}_{2}$ Content and Antioxidant Activities in Wheat Plants}

$\mathrm{H}_{2} \mathrm{O}_{2}$ content was determined as previously described [30,58], using $50 \mathrm{mg}$ of fresh plant material that was taken from 40 -day-old wheat plants. The results were expressed as micromoles per gram of fresh weight. Four biological replicates per treatment and condition were analyzed.

Three antioxidant enzymatic activities, superoxide dismutase (SOD), peroxidase (POD), and catalase (CAT), that were related to ROS scavenging were analyzed as previously described [30,59], using wheat leaves that were detached from 40-day-old plants and immediately frozen in liquid nitrogen. Proteins were extracted from $50 \mathrm{mg}$ of plant material homogenized in $50 \mathrm{mM}$ potassium phosphate buffer ( $\mathrm{pH}$ 7.8), and their concentration was determined as previously described [52]. SOD, POD, and CAT activities were expressed as units per minute per milligram of protein. A total of four biological replicates per treatment and condition were analyzed.

\subsection{Statistical Analyses}

IBM SPSS $^{\circledR}$ Statistics 27 (IBM Corp.) was used for the statistical analyses through an analysis of variance (ANOVA) using Tukey's and Duncan's test (the latter for data of antioxidant activities and $\mathrm{H}_{2} \mathrm{O}_{2}$ content) to identify the significant differences among the samples $(p<0.05)$. A two-way ANOVA was used to test for possible interactions between the main effects within each set of data, followed by a mean separation using Tukey's test $(p<0.05)$. 


\section{Results}

\subsection{Isolation of Endophytic Fungi from Wheat Roots, Selection and Genus Assignment}

Using plant material that was collected from a field assay [39], 768 wheat root pieces of $1 \mathrm{~cm}$ length, that were cut from previously washed and sonicated roots, were plated on PDA chloramphenicol and, as a result, 54 isolates showing different phenotypes were selected (Supplementary Figure S1). The sequence analysis of the ITS1-ITS4 region distributed them into 16 fungal genera (Supplementary Table S1). Members of the Fusarium genus were the most prevalent among the 54 isolates $(37.04 \%)$, followed by the genera Alternaria $(13 \%)$, Monosporascus (13\%), and Trichoderma (7.5\%); 21 out of 54 were able to grow in PDB with $40 \%$ PEG. This percentage of PEG is equivalent to a water potential of $-1.76 \mathrm{MPa}$, and although some of the isolates were affected by this simulated drought stress, it was not a constant for all fungi that were tested. Moreover, no correlation was found between belonging to a fungal genus and growing at a given PEG concentration, suggesting an isolate-dependent property. The four isolates of the genus Trichoderma that grew to different extents in PDB plus 40\% PEG were chosen for further testing.

\subsection{Characterization of Trichoderma Strains Endophytes of Wheat}

The Trichoderma strains T136, T137, T138, and T139, that were isolated from the wheat root endosphere were molecularly identified at the species level by sequence analysis of the ITS1-ITS4 region, a fragment of ca. $600 \mathrm{bp}$ in length of the tef1 $\alpha$ gene and a fragment of ca. $850 \mathrm{bp}$ in length of the acl1 gene. The acl1 sequence that was obtained for T139 was not clean enough for sequencing, although this did not prevent its identification. The accession numbers of their sequences were deposited in the GenBank and are shown in Table 1. As they had sequences that were identical to those of ex-type strains or representative species that were available in databases, they were identified as: T. harzianum T136, T. simmonsii T137, T. afroharzianum T138, and T. harzianum T139.

Table 1. Species assignment and accession numbers of Trichoderma strains isolated from the wheat endosphere in this study.

\begin{tabular}{ccccc}
\hline Strain & Identified as & ITS1-ITS4 & tef1 $\boldsymbol{\alpha}$ & acl1 \\
\hline T136 & T. harzianum & MT706636 & MW803052 & MW803056 \\
T137 & T. simmonsii & MT706637 & MW803053 & MW803057 \\
T138 & T. afroharzianum & MT706638 & MW803054 & MW803058 \\
T139 & T. harzianum & MW794309 & MW803055 & no data \\
\hline
\end{tabular}

\subsection{Trichoderma Strains Show Different Biocontrol Potential against Fg}

The biocontrol potential of strains T136, T137, T138, and T139 against $F g$ were tested using different in vitro assays. All Trichoderma strains were able to inhibit the Fg colony growth in dual cultures (Table 2), although two different antagonistic behaviors were observed. Strains T136 and T139 overgrew the Fg colony in four days in co-cultures, while strains T137 and T138 did not (Figure 2A). In addition, strains T136 and T139 differed significantly from the other two strains in their ability to inhibit pathogen colony growth (Table 2). To determine whether VOCs that were produced by these Trichoderma strains may reduce $\mathrm{Fg}$ growth, we confronted both fungi in partitioned Petri dishes (Figure 2B). VOCs that were produced by strain T138 appeared to have antifungal activity against $F g$, while inhibition was not observed for the other three strains. 
Table 2. Inhibition of Fusarium graminearum $(F g)$ colony growth by four Trichoderma strains (T. harzianum T136, T. simmonsii T137, T. afroharzianum T138, and T. harzianum T139) ${ }^{1}$.

\begin{tabular}{cccc}
\hline Strain & Dual Culture (\%) $\mathbf{~}^{\mathbf{2}}$ & $\begin{array}{c}\text { Cellophane } \\
\text { Membrane (\%) }\end{array}$ & $\begin{array}{c}\text { Cellulose Membrane } \\
\mathbf{( \% )}^{\mathbf{3}}\end{array}$ \\
\hline T136 & $90.3 \pm 4.2 \mathrm{a}$ & $76.2 \pm 0.4 \mathrm{a}$ & $53.8 \pm 2.4 \mathrm{a}$ \\
T137 & $58.1 \pm 7.2 \mathrm{~b}$ & $34.8 \pm 0.1 \mathrm{~b}$ & $22.6 \pm 0.6 \mathrm{~b}$ \\
T138 & $40.5 \pm 4.3 \mathrm{~b}$ & $22.5 \pm 8.5 \mathrm{~b}$ & $16.4 \pm 6.4 \mathrm{~b}$ \\
T139 & $85.2 \pm 5.6 \mathrm{a}$ & $69.2 \pm 1.4 \mathrm{a}$ & $49.3 \pm 0.6 \mathrm{a}$ \\
\hline
\end{tabular}

${ }^{1}$ Results are expressed as the inhibition percentage with respect to the mean colony diameter of $F g$ grown alone. Values are the means of four replicates with the corresponding standard deviations. Different letters indicate differences within each column according to one-way analysis of variance (ANOVA) followed by Tukey's test $(p<0.05) .{ }^{2}$ Dual culture data were obtained after four-day growth on PDA. ${ }^{3} \mathrm{Fg}$ diameters were measured after three days of growth on the same PDA on which Trichoderma grew on cellophane or 12.5-kDa cut-off cellulose membrane for $36 \mathrm{~h}$.

A

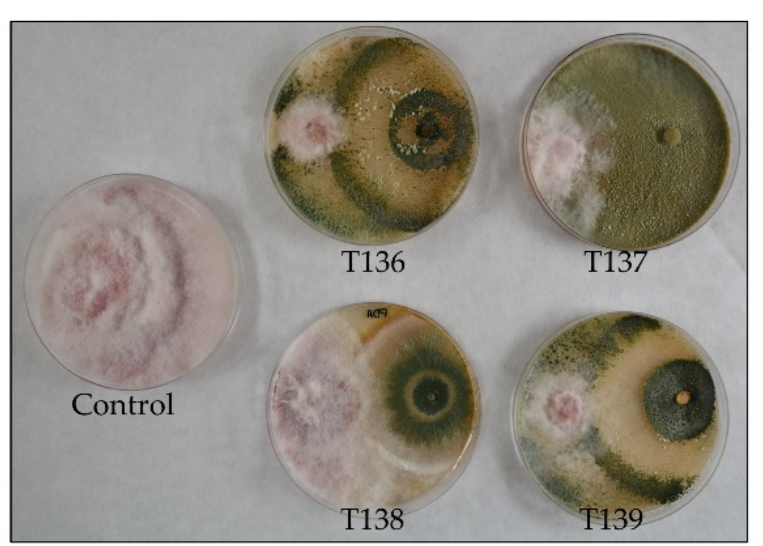

B

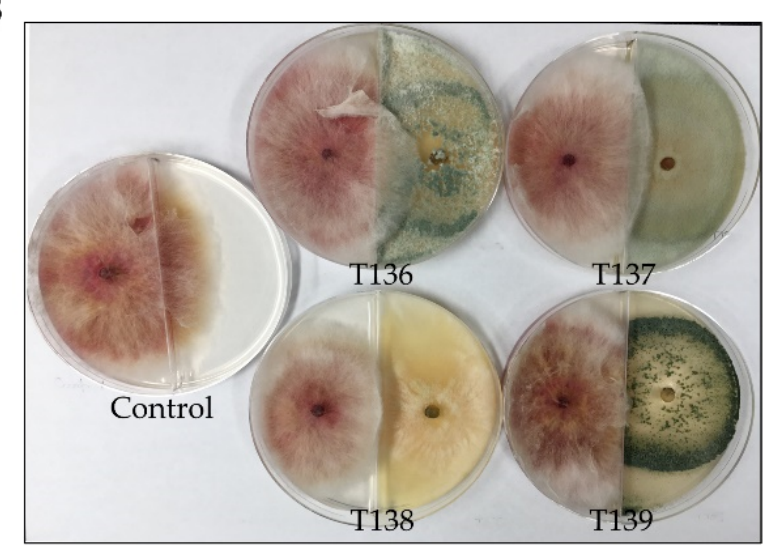

Figure 2. Dual cultures of four Trichoderma strains (T. harzianum T136, T. simmonsii T137, T. afroharzianum T138, and T. harzianum T139) (on the right of each plate) and the pathogen Fusarium graminearum (on the left). (A) Using $8.5 \mathrm{~cm}$ Petri plates, and (B) using centrally partitioned $8.5 \mathrm{~cm}$ Petri plates. Control corresponds to the pathogen growing alone. The plates were incubated at $28^{\circ} \mathrm{C}$ for four days.

To determine the capability of Trichoderma extracellular compounds to inhibit $F g$ colony growth, the four Trichoderma strains were grown on PDA with cellulose or cellophane membranes on the surface of the culture medium to allow the introduction of Trichoderma extracellular compounds into the agar medium. After removing the membranes, the effect of different Trichoderma extracellular compounds on $\mathrm{Fg}$ growth was determined. The results are shown in Table 2. As was the case with the dual culture assay, all strains inhibited the growth of $F g$, and strains T136 and T139 showed the best results in the membrane tests.

The biocontrol potential of the four Trichoderma strains was also evaluated by measuring the extracellular protease, cellulase, and chitinase enzymatic activities in $\mathrm{SM}+2 \% \mathrm{Glu}$ and $\mathrm{SM}+0.5 \% \mathrm{Fg}$-CWs cultures (Table 3). Protease and chitinase activities were detected for the four strains in both culture media, apart from protease activity for T138 in SM $+2 \%$ Glu. No cellulase activity was detected in $\mathrm{SM}+2 \%$ Glu medium. The highest levels of protease activity were detected for strain T136 in SM $+2 \%$ Glu. However, the highest levels of cellulase and chitinase activities were detected for strain T136 in SM $+0.5 \% \mathrm{Fg}$-CWs $(p<0.01)$. A two-way ANOVA showed the effect of the variable "strain" $(p<0.001$, for both protease and cellulase activities; $p<0.01$, for chitinase activity) and the variable "medium" $(p<0.001$, for both protease and cellulase activities; $p<0.01$, for chitinase activity), and the combination "strain $\mathrm{x}$ medium" $(p<0.001)$ for all three activities. 
Table 3. Protease, cellulase, and chitinase activities that were measured for four Trichoderma strains (T. harzianum T136, T. simmonsii T137, T. afroharzianum $\mathrm{T} 138$, and T. harzianum $\mathrm{T} 139$ ) in extracellular protein extracts from two culture media ${ }^{1}$.

\begin{tabular}{ccccccc}
\hline \multirow{2}{*}{ Strain } & \multicolumn{2}{c}{ Synthetic Medium $+\mathbf{2} \%$ Glucose } & \multicolumn{2}{c}{ Synthetic Medium $+\mathbf{0 . 5} \%$ Fg-Cell Walls } \\
\cline { 2 - 6 } & Protease $^{2}$ & Cellulase $^{2}$ & Chitinase $^{2}$ & Protease $^{2}$ & Cellulase $^{\mathbf{2}}$ & Chitinase $^{2}$ \\
\hline T136 & $175.3 \pm 43.5 \mathrm{a}$ & 0.0 & $1.4 \pm 0.2 \mathrm{~b}$ & $93.8 \pm 5.7 \mathrm{a}$ & $7.8 \pm 0.6 \mathrm{a}$ & $24.0 \pm 5.6 \mathrm{a}$ \\
$\mathrm{T} 137$ & $136.4 \pm 7.9 \mathrm{ab}$ & 0.0 & $5.5 \pm 0.9 \mathrm{ab}$ & $39.1 \pm 8.6 \mathrm{~b}$ & $2.6 \pm 0.2 \mathrm{c}$ & $7.0 \pm 0.4 \mathrm{bc}$ \\
$\mathrm{T} 138$ & $0.0 \mathrm{c}$ & 0.0 & $13.1 \pm 5.1 \mathrm{a}$ & $86.6 \pm 5.5 \mathrm{a}$ & $3.3 \pm 0.3 \mathrm{c}$ & $14.1 \pm 0.8 \mathrm{~b}$ \\
$\mathrm{~T} 139$ & $78.6 \pm 18.4 \mathrm{~b}$ & 0.0 & $8.2 \pm 3.7 \mathrm{ab}$ & $91.0 \pm 9.3 \mathrm{a}$ & $5.5 \pm 1.1 \mathrm{~b}$ & $4.1 \pm 0.4 \mathrm{c}$ \\
\hline
\end{tabular}

${ }^{1}$ Extracellular protein was obtained from five day liquid cultures in a synthetic medium supplemented with $2 \%$ glucose or $0.5 \%$ Fusarium graminearum $(F g)$ cell walls. ${ }^{2}$ The data are expressed in micromoles of azocasein (protease activity), carboxymethylcellulose (cellulase activity), and $\mathrm{N}$-acetylglucosamine (chitinase activity) in $1 \mathrm{~min}$ per milligram of protein. The values are the means of three replicates with the corresponding standard deviations. Different letters indicate the differences within each column according to one-way analysis of variance (ANOVA) followed by Tukey's test $(p<0.05)$.

\subsection{Trichoderma Strains Show Differences in ACCD Activity and Phytohormone Production}

To obtain data that were related to plant beneficial effects of the four Trichoderma strains, ACCD activity and the production of eight phytohormones were investigated. The specific ACCD activity detected after growing Trichoderma in a SM medium for four days is shown in Figure 3. All of the strains displayed ACCD activity, the highest being T. simmonsii T137 $(p<0.05)$.

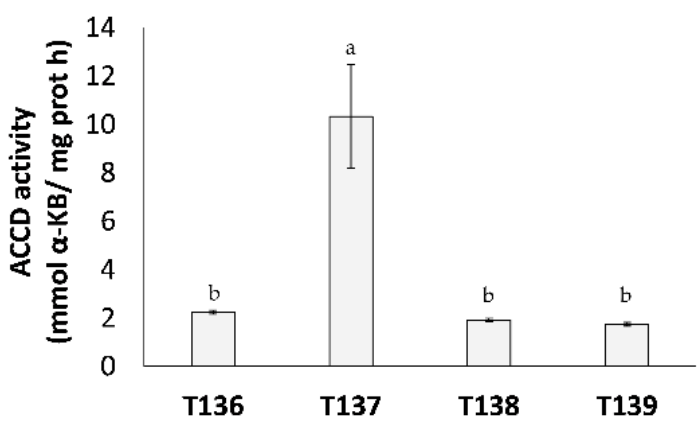

Figure 3. The 1-aminocyclopropane-1-carboxylic acid deaminase (ACCD) activity of four Trichoderma strains (T. harzianum T136, T. simmonsii T137, T. afroharzianum T138, and T. harzianum T139), expressed as millimoles of $\alpha$-ketobutyrate in $1 \mathrm{~h}$ per milligram of protein, in a four day synthetic medium culture. The data were calculated from three replicates for each strain. Different letters above the bars indicate significant differences according to one-way analysis of variance (ANOVA) followed by Tukey's test $(p<0.05)$.

The levels of IAA, ABA, DHZ, iP, $\mathrm{tZ}, \mathrm{SA}, \mathrm{GA}_{4}$, and $\mathrm{GA}_{1}$ that were detected in lyophilized Trichoderma supernatants from two day PDB and PDB-Trp cultures, compared with those that were detected in the corresponding uninoculated controls, are shown in Figure 4. The production of the eight phytohormones was detected in Trichoderma. In comparison with the controls, the production of SA by T138, of ABA by T136 and T139, and of $\mathrm{GA}_{4}, \mathrm{GA}_{1}$ and $\mathrm{tZ}$ by T137 and T138, was not detected. IAA production in the four strains positively responded to the addition of Trp to the fungal culture medium. However, a negative relationship was observed in all four strains between the production of $\mathrm{tZ}$ or $\mathrm{GA}_{1}$ and the addition of Trp to the medium. According to a two-way ANOVA, there was an effect of the variable "strain" and variable "medium" and their combination "strain $\times$ medium", on the production of five out of the eight phytohormones that were investigated (Figure 4). Strain T137 was notable in the production of ABA and iP in both media $(p<0.05)$ and of DHZ in PDB-Trp $(p<0.05)$. Moreover, production of IAA was significantly higher in strains T137 and T139 compared with those that were detected for T136 and T138 in PDB-Trp $(p<0.05)$, while SA production was only detected in T136 and T139 supernatants from this last medium $(p<0.05)$. 
A

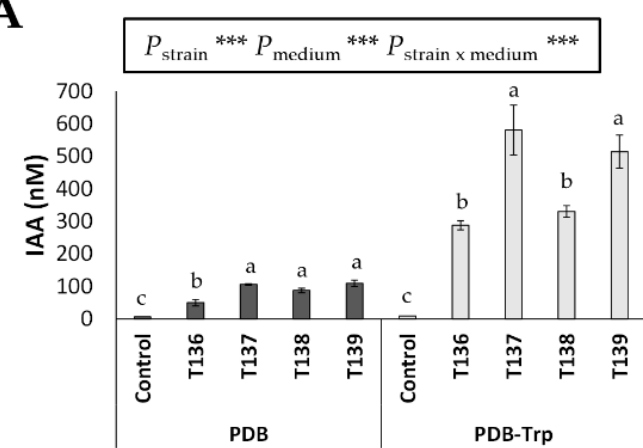

C

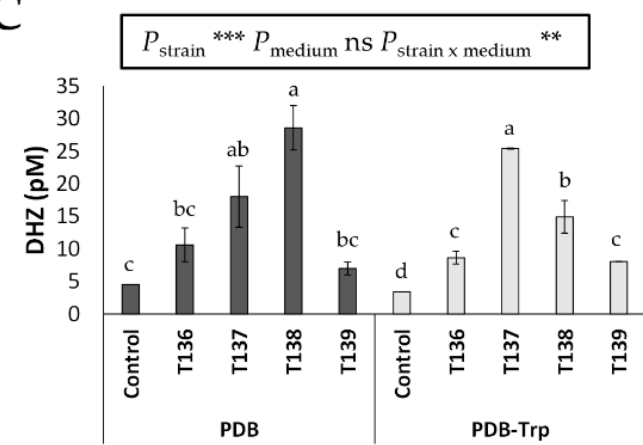

E

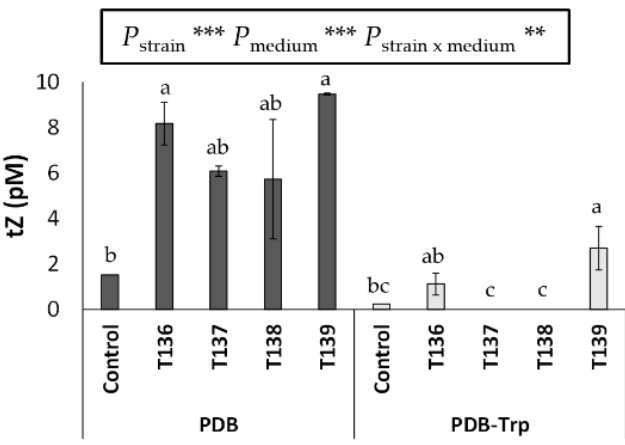

G

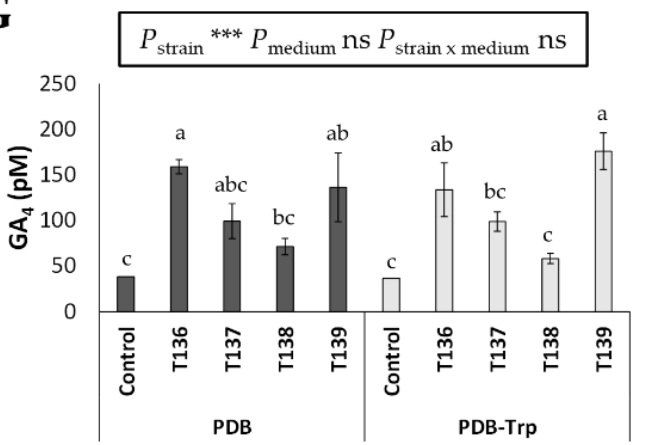

B

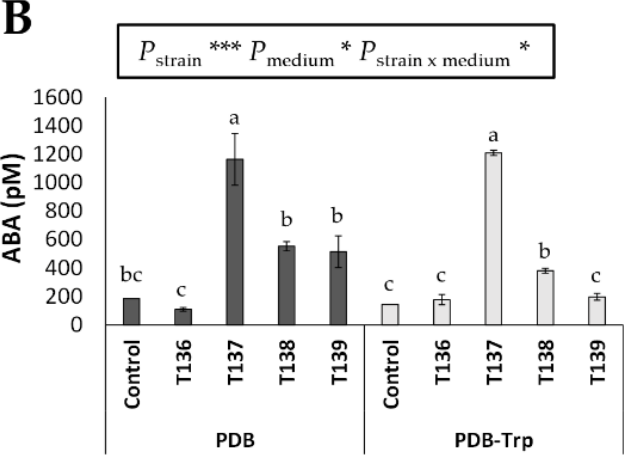

D

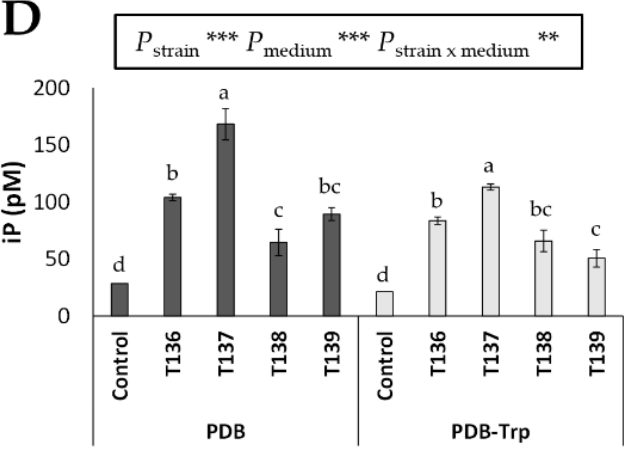

F
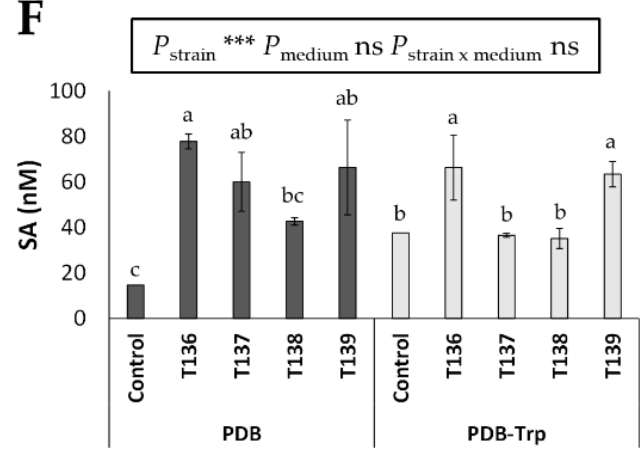

H

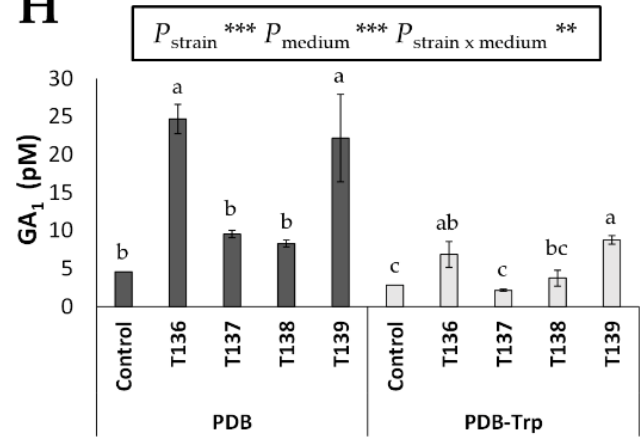

Figure 4. Phytohormone production in two day PDB and PDB-tryptophan (Trp) cultures by four Trichoderma strains (T. harzianum T136, T. simmonsii T137, T. afroharzianum T138, and T. harzianum T139) compared to their respective PDB and PDB-Trp media controls. (A) Indole-3-acetic acid (IAA), (B) abscisic acid (ABA), (C) cytokinin dihydrozeatin (DHZ), (D) cytokinin isopentenyladenine (iP), (E) cytokinin trans-zeatin (tZ), (F) salicylic acid (SA), (G) gibberellin 4 (GA 4 ), and (H) gibberellin 1 GA1 $\left(\mathrm{GA}_{1}\right)$. The data were calculated from three replicates per strain and culture medium. For each phytohormone and culture medium, different letters above the bars indicate significant differences according to oneway analysis of variance (ANOVA) followed by Tukey's test $(p<0.05)$. For each phytohormone, significant effects were determined by a two-way ANOVA for Trichoderma strain, culture medium, and the combination strain per culture medium ${ }^{* * *}: p<0.001{ }^{* *}: p<0.001 ; *: p<0.05 ;$ ns: no statistical differences). 


\subsection{Efficient Colonizers of Wheat Roots Even if Applied Together}

To evaluate the ability of T136, T137, T138, and T139 strains that were isolated from the endosphere of Berdun $\mathrm{R}$ wheat to colonize Basilio wheat roots when applied alone or with all four mixed together, we estimated the proportion of fungal DNA vs. plant DNA from qPCR data that were obtained from 10-day-old seedling roots at $48 \mathrm{~h}$ after inoculation of Trichoderma. As shown in Table 4, Trichoderma was not detected in the root samples from uninoculated plants, while all strains were able to colonize the roots of Basilio seedlings. No differences in colonization were detected among the four strains and the Mix.

Table 4. Root colonization of wheat plants of the variety Basilio by four Trichoderma strains (T. harzianum T136, T. simmonsii T137, T. afroharzianum T138, and T. harzianum T139) ${ }^{1}$.

\begin{tabular}{cccccc}
\hline \multirow{2}{*}{ Strain } & \multicolumn{2}{c}{ Trichoderma Actin } & \multicolumn{2}{c}{ Wheat Actin } & Ratio $^{\mathbf{5}}$ \\
\cline { 2 - 6 } & Ct $^{\mathbf{2}}$ & Qyt (ng) $^{\mathbf{3}}$ & $\mathbf{C t}^{\mathbf{2}}$ & Qty (ng) $^{\mathbf{4}}$ & \\
\hline Uninoculated & $29.45 \pm 0.14$ & - & $22.11 \pm 0.29$ & $4.02 \pm 0.54$ & $0.0 \mathrm{~b}$ \\
T136 & $14.62 \pm 0.61$ & $9.36 \pm 1.08$ & $22.48 \pm 0.28$ & $3.32 \pm 0.52$ & $2.89 \pm 0.78$ a \\
T137 & $14.53 \pm 0.22$ & $9.51 \pm 0.40$ & $22.70 \pm 0.42$ & $2.92 \pm 0.77$ & $3.41 \pm 0.92 \mathrm{a}$ \\
T138 & $14.74 \pm 0.89$ & $9.14 \pm 1.58$ & $22.72 \pm 0.25$ & $2.89 \pm 0.45$ & $3.24 \pm 0.93 \mathrm{a}$ \\
T139 & $15.55 \pm 0.41$ & $7.71 \pm 0.73$ & $22.96 \pm 0.55$ & $2.45 \pm 1.01$ & $3.37 \pm 1.09$ a \\
Mix & $16.42 \pm 0.48$ & $6.16 \pm 0.84$ & $23.41 \pm 0.25$ & $1.63 \pm 0.46$ & $3.86 \pm 0.57$ a \\
\hline
\end{tabular}

${ }^{1}$ Fungal DNA was quantified by qPCR. The data were calculated from four replicates per strain, and the values presented as means with the corresponding standard deviations. ${ }^{2} \mathrm{Ct}$, threshold cycle. ${ }^{3}$ Quantity of Trichoderma DNA (ng), referred to as Trichoderma actin gene, -: negative values. ${ }^{4}$ Quantity of wheat DNA (ng), referred to as wheat actin gene. ${ }^{5}$ Proportion of fungal DNA vs. plant DNA; values with different letters are significantly different according to one-way analysis of variance (ANOVA) followed by Tukey's test $(p<0.05)$.

The abundance of Trichoderma strains in 21 day samples was $2.4 \times 10^{5}, 0.7 \times 10^{5}$, $4.3 \times 10^{5}$ and $4.9 \times 10^{5}$ cfu per wheat plant root for strains T136, T137, T138, and T139, respectively. No Trichoderma colonies were observed in the roots of the control treatment. Regarding the Mix treatment, Trichoderma abundance was found to be in a similar range, $1 \times 10^{5}$, to individual inoculations. An analysis of the count data showed no differences among the Trichoderma treatments. In addition, considering the colony phenotypes on PDA, the four strains had similar percentage counts in the Mix treatment.

\subsection{Trichoderma Strains had Different Effects on Wheat Plants}

Trichoderma strains T136, T137, T138, and T139 were tested in an in vivo assay to study the effect on wheat plant growth promotion and the drought stress alleviation of plants when fungi were applied separately or in combination. The effect of these strains on plant emergence, tillering, and plant growth are shown in Table 5. At 6 days, the lowest emergence rate was recorded for the control treatment, at $46.7 \%(p<0.05)$, and the highest rates were 83.3 and 80\%, observed, respectively, in the T137 and T136 treatments $(p<0.05)$. However, no significant differences were detected in the emergence rates among treatments at 9 days. This result showed that the application of any of the four Trichoderma strains or the Mix to the plant growth substrate advanced the germination of Basilio wheat seeds. As shown in Table 5, data of the tillering rate that were recorded at 35 days also showed that this parameter was significantly increased by the five Trichoderma treatments, at least under optimal irrigation conditions. The highest tillering rate value was recorded for the Mix treatment in the absence of water stress. Interestingly, under water stress conditions, tillering was observed in all plants of the T138 treatment, and in none of the T136 treatment. Analysis of the fresh weight data that were recorded in 40-day-old plants showed differences among treatments. Under optimal irrigation, the control plants showed the lowest values compared to those from plants of the other treatments. However, under water stress conditions, no differences in fresh weight were observed between the control and T136-treated plants and they showed the lowest values compared to those of the other four Trichoderma treatments. A two- 
way ANOVA for the fresh weight results showed the effect of the variable "treatment" $(p<0.001)$ and of the variable "irrigation condition" $(p<0.001)$, but no showed significance for the combination of both factors.

Table 5. Effect of five Trichoderma treatments (T. harzianum T136, T. simmonsii T137, T. afroharzianum T138, T. harzianum T139, and a mixture with these four strains) on emergence, tillering, and fresh weight of Basilio wheat grown in a greenhouse under optimal irrigation and water stress (irrigation was removed for 2.5 weeks when plants were 21 days old) conditions.

\begin{tabular}{ccccccc}
\hline \multirow{2}{*}{ Treatment } & \multicolumn{2}{c}{ Emergence Rate (\%) $\mathbf{1}^{\mathbf{1}}$} & \multicolumn{2}{c}{ Tillering Rate (\%) $^{\mathbf{2}}$} & \multicolumn{2}{c}{ Fresh Weight (g) $^{\mathbf{3}}$} \\
\cline { 2 - 6 } & 6 Das & 9 Das & Optimal Irrigation & Water Stress & Optimal Irrigation & Water Stress \\
\hline Control & $46.7 \pm 13.9 \mathrm{c}$ & $76.7 \pm 19 \mathrm{a}$ & $16.7 \mathrm{c}$ & $25.0 \mathrm{c}$ & $0.64 \pm 0.08 \mathrm{c}$ & $0.60 \pm 0.08 \mathrm{c}$ \\
T136 & $80.0 \pm 7.5 \mathrm{a}$ & $93.3 \pm 9.1 \mathrm{a}$ & $66.7 \mathrm{~b}$ & $0.0 \mathrm{~d}$ & $0.94 \pm 0.15 \mathrm{ab}$ & $0.61 \pm 0.10 \mathrm{bc}$ \\
T137 & $83.3 \pm 11.8 \mathrm{a}$ & $96.7 \pm 7.5 \mathrm{a}$ & $66.7 \mathrm{~b}$ & $50.0 \mathrm{c}$ & $0.99 \pm 0.06 \mathrm{a}$ & $0.80 \pm 0.09 \mathrm{ab}$ \\
T138 & $76.7 \pm 14.9 \mathrm{ab}$ & $93.3 \pm 9.1 \mathrm{a}$ & $83.3 \mathrm{ab}$ & $100.0 \mathrm{a}$ & $1.15 \pm 0.16 \mathrm{a}$ & $0.91 \pm 0.14 \mathrm{a}$ \\
T139 & $63.3 \pm 7.45 \mathrm{bc}$ & $83.3 \pm 16.7 \mathrm{a}$ & $66.7 \mathrm{~b}$ & $40.0 \mathrm{c}$ & $0.95 \pm 0.09 \mathrm{ab}$ & $0.81 \pm 0.12 \mathrm{ab}$ \\
Mix & $70.0 \pm 13.9 \mathrm{~b}$ & $90 \pm 14.9 \mathrm{a}$ & $90.0 \mathrm{a}$ & $70.0 \mathrm{~b}$ & $1.20 \pm 0.16 \mathrm{a}$ & $0.82 \pm 0.05 \mathrm{a}$ \\
\hline
\end{tabular}

${ }^{1}$ Data taken at six and nine days after sowing are expressed in percentages and were calculated in 16 replicates per treatment $(n=16)$.

2 Data that were recorded in 35-day-old plants are expressed in percentages and were calculated in eight replicates per treatment and condition $(n=8) .{ }^{3}$ Data that were recorded in 40-day-old plants are expressed in $\mathrm{g}$ and were calculated in eight replicates per treatment and condition $(n=8)$. All the values are means with the corresponding standard deviations. Different letters indicate differences within each column according to one-way analysis of variance (ANOVA) followed by Tukey's test $(p<0.05)$.

The analysis of endogenous $\mathrm{H}_{2} \mathrm{O}_{2}$ content that was recorded from 40-day-old plants did not show differences between any of the Trichoderma treatments and the control in plants under the optimal irrigation condition (Figure 5A). Differences were seen between plants that were treated with strain T138, which achieved higher $\mathrm{H}_{2} \mathrm{O}_{2}$ values, and those from the T137 and Mix treatments $(p<0.05)$. Water-stressed control plants showed significantly higher levels of $\mathrm{H}_{2} \mathrm{O}_{2}$ compared to those that were treated with Trichoderma, which, in turn, presented significant differences, with the lowest value obtained in plants of the T137 treatment. In addition, the effect of the variable "treatment" $(p<0.01)$ and the variable "irrigation condition" $(p<0.01)$ was detected by a two-way ANOVA. In parallel, no difference was detected for SOD and POD activities between plants of any of the five Trichoderma treatments and the control plants under optimal irrigation conditions (Figure 5B,C). The highest levels of CAT activity in unstressed plants were detected for the T136 treatment (Figure 5D). In contrast, differences among treatments were observed for the three enzymatic activities in water-stressed plants. In this sense (Figure 5B-D), plants of the T137 and T138 treatments presented the highest levels of SOD and those of the T137 and Mix treatments had the highest levels of POD $(p<0.05)$, while the lowest values of CAT occurred in plants of the Mix treatment. Differences in the effect of the two variables, "treatment" and "irrigation", and of their combination, were observed for these three activities by a two-way ANOVA. For SOD, the effect of the variable "irrigation" $(p<0.001)$ and the combination of variables "treatment $x$ irrigation" $(p<0.05)$; for POD, the effect of the combination of both variables $(p<0.05)$; and for CAT, the effect of the variable "treatment" $(p<0.001)$ and the combination "treatment $x$ irrigation" $(p<0.05)$ were detected. 
A

$$
P_{\text {treatment }}{ }^{* *} P_{\text {irrigation }}{ }^{* *} P_{\text {treatment } x \text { irrigation }} \mathrm{ns}
$$
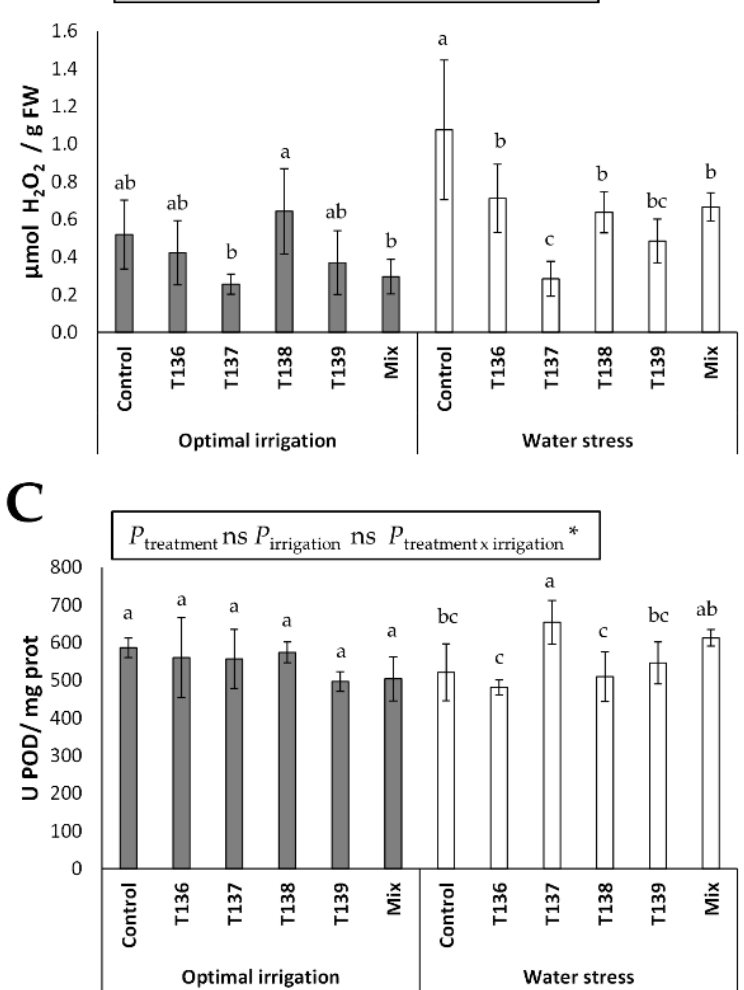
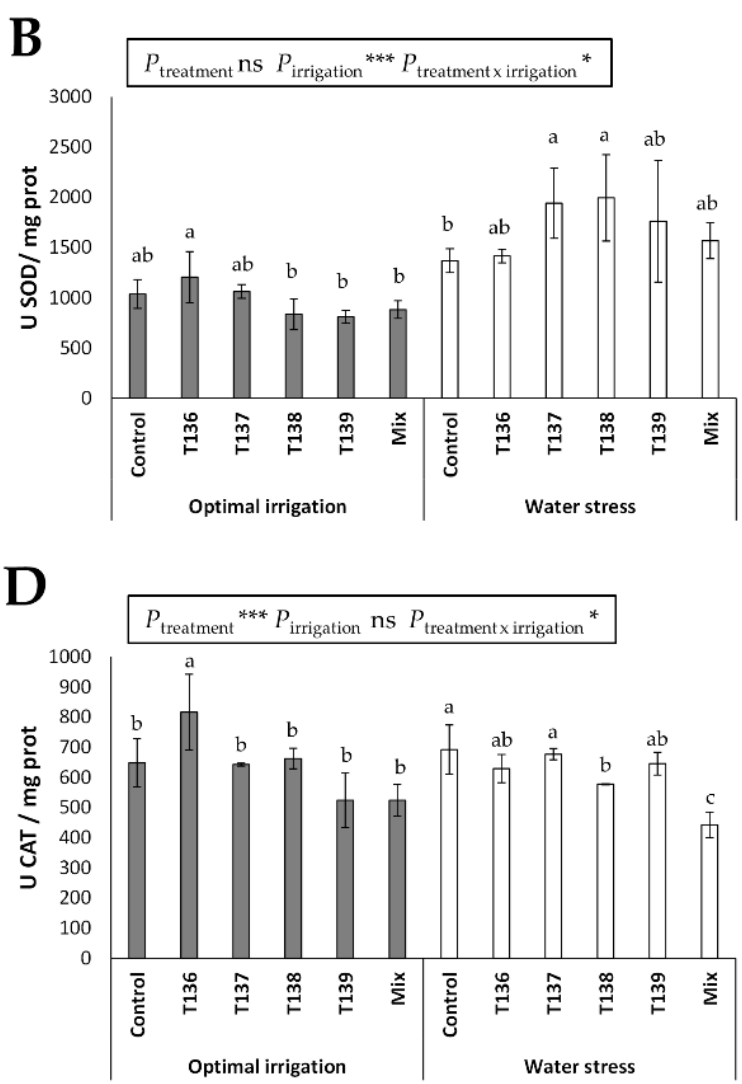

Figure 5. Effect of Trichoderma (T. harzianum T136, T. simmonsii T137, T. afroharzianum T138, T. harzianum T139, and a mixture with these four strains) treatments on (A) $\mathrm{H}_{2} \mathrm{O}_{2}$ content, and (B) SOD, (C) POD, and (D) CAT activities in 40-day-old wheat plants that were grown under optimal irrigation and water stress (irrigation was removed for 2.5 weeks when plants were 21 days old) conditions. The data were calculated from four replicates for each treatment and condition $(n=4)$, and different letters above the bars indicate significant the differences according to one-way analysis of variance (ANOVA) followed by Duncan's test $(p<0.05)$. For each set of data, the effect of significance was determined by a two-way ANOVA for Trichoderma treatment, irrigation condition, and the combination treatment per irrigation condition $\left({ }^{* *}: p<0.001 ;{ }^{* *}: p<0.01 ;{ }^{*} p<0.05\right.$; ns: no statistical differences). FW: leaf fresh weight.

To study the effect of the five Trichoderma treatments long-term, the greenhouse assay was maintained for five months and all plants were watered as needed when they reached 40 days. The representative plants and spikes from the different treatments and the two irrigation conditions are shown in Figure 6A,B. No differences in plant height and spike weight values were detected among treatments under the optimal irrigation condition, since Trichoderma-treated plants gave values similar to those of the control (Figure 6B,C). However, significant differences in these two parameters were detected among treatments under the water stress condition; this started at 21 days and was maintained for up to 2.5 weeks. Plants of the control and T136 treatments gave the lowest values of plant height, and together with those from the T139 treatment, also presented the lowest values of spike weight. Little variability among replicates was observed for these parameters in plants that were treated with strain T137. The two-way ANOVA for height results showed an effect for the variable "treatment" $(p<0.001)$ and the variable "irrigation" $(p<0.001)$, and for the combination of both factors $(p<0.01)$. For spike weight, the results showed an effect for "treatment" and effect for "irrigation" ( $p<0.01)$, but no effect for their combination $(p>0.05)$. 
A

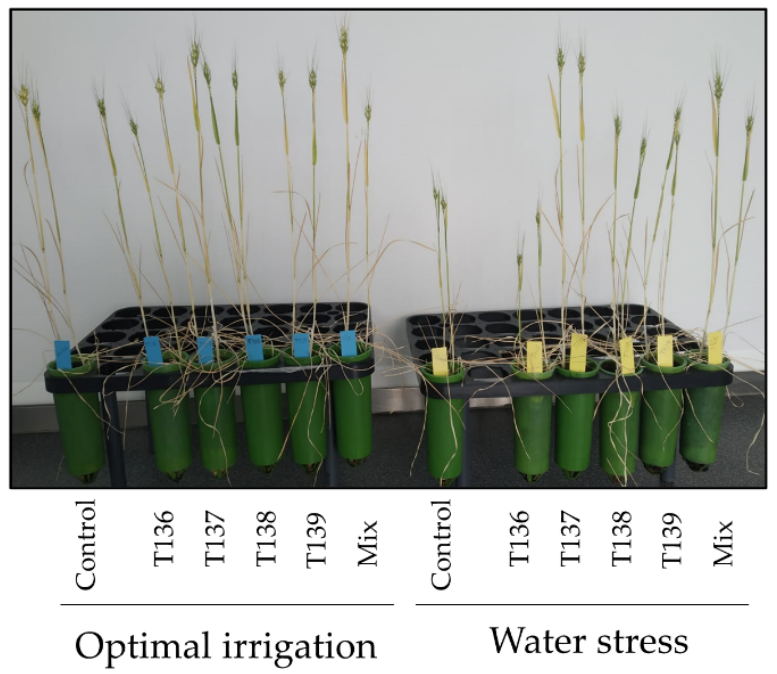

B

\begin{tabular}{|c|c|c|c|c|c|}
\hline Control & T136 & T137 & T138 & T139 & Mix \\
\hline 14 & 48 & 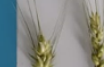 & 18 & y $y$ & 4 \\
\hline
\end{tabular}

Optimal irrigation

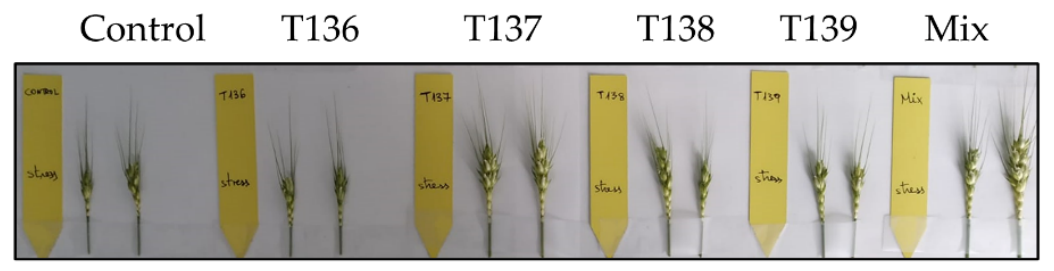

Water stress

C

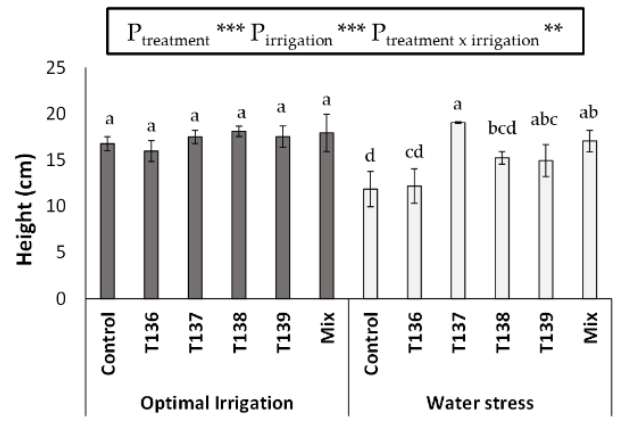

D

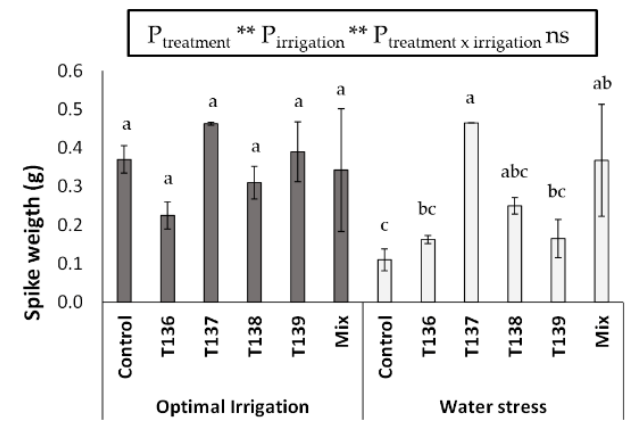

Figure 6. Long-term effect of Trichoderma (T. harzianum T136, T. simmonsii T137, T. afroharzianum T138, T. harzianum T139, and a mixture with these four strains) treatments on Basilio wheat under optimal irrigation and water stress (irrigation was removed for 2.5 weeks when the plants were 21 days old) conditions. Photographs of (A) plants and (B) spikes, taken at 5 months, and values of (C) plant height and (D) spike weight. Data in (C,D) were calculated from four replicates for each treatment and condition $(n=4)$, and the different letters above the bars indicate significant differences according to one-way analysis of variance (ANOVA) followed by Tukey's test $(p<0.05)$. For each set of data, the effect of significance was determined by a two-way ANOVA for Trichoderma treatment, irrigation condition, and the combination treatment per irrigation condition $\left(* * *: p<0.001 ;{ }^{* *}: p<0.01{ }^{*} p<0.05\right.$; ns: no statistical differences). 


\section{Discussion}

Wheat is one of the world's most important food crops, but climate change, which is causing rising temperatures and an increase of arid and semi-arid arable lands, is leading losses that are often unaffordable. To cope with problems such as attacks by pathogens such as $F g$, which takes advantage of plant weakness and drought, we have adopted a strategy that was based on the isolation and selection of Trichoderma endophytic strains from wheat. Initially, we isolated 54 culturable endophytic fungi from the roots of healthy plants that were grown in the field under non-irrigated conditions. Interestingly, Fusarium spp. isolates were prevalent, making up more than one third of the wheat root endosphere in our trial. Although several species of Fusarium are recognized as wheat pathogens, the Fusarium isolates that were collected in our study were obtained from the root endosphere of heathy plants. Endophytic isolates of Fusarium spp. have been described as useful for controlling root and vascular diseases that are caused by oomycetes and fungi [60]. Thus, these wheat endophytic isolates of Fusarium should be further investigated since they may not be detrimental and may even be beneficial for the crop. A total of four endophytic strains of Trichoderma were also isolated and assigned to three species [7]: T. harzianum, T. simmonsii, and T. afroharzianum. All belong to the former species complex "T. harzianum" [18], a species that has many strains that are used as BCAs [11,12]. Although T. simmonsii is a common soil inhabitant [18], a recent report also described it as an endophyte in bell pepper plants [61]. Root colonization ability is often a criterion for selecting Trichoderma strains that are beneficial to plants [23], and we observed by qPCR analysis that wheat plants of the Basilio variety are suitable hosts for the four Trichoderma isolates that were obtained from the wheat root endosphere of the Berdun R variety when applied alone or in combination to seedlings. qPCR colonization data that were obtained $48 \mathrm{~h}$ after 10-day-old seedling inoculation with Trichoderma in liquid medium were in line with those obtained by assessing Trichoderma survival in three-week-old plants that were grown under greenhouse conditions. Data that were obtained in both experiments for individual inoculations and the Mix treatment showed an absence of negative interactions among the four Trichoderma strains, indicating compatibility when mixed.

To compare the antagonistic properties of the four Trichoderma strains against $F g$, different in vitro inhibition tests were carried out. T. harzianum T136 and T139 showed the best performances in dual cultures and membrane assays, indicating that mycoparasitism, competition for space and nutrients, and antibiosis may be involved in their biocontrol activity against this pathogen. The capability of T. harzianum to antagonize different phytopathogenic Fusarium spp. has been previously reported $[62,63]$. Greater inhibition of $\mathrm{Fg}$ colony growth on cellophane membranes in comparison to that which was observed on dialysis membranes indicates that the antifungal activity of both strains of T. harzianum is due to the combined effects of secreted low and high molecular weight compounds. This result contrasts with previous studies showing that metabolites that are produced by Trichoderma spp. are the main contributors to the antifungal activity of these species against plant pathogenic Fusarium spp. $[13,63,64]$. The test that was performed in partitioned plates showed that VOCs are also involved in the antagonism of T. afroharzianum T138 against $F g$. The antifungal activity of VOCs from endophytic T. afroharzianum strains against Fusarium spp. has recently been reported [65]. The production of fungal CW degrading enzymes by Trichoderma spp. is fully recognized $[19,66]$ and their effect is synergistic with the antibiotic activity that is displayed by secondary metabolites against different soilborne phytopathogenic fungi [67]. In the present study, protease, cellulase, and chitinase activities were determined in extracellular protein extracts for the four Trichoderma strains after growing them in a synthetic medium containing glucose or $\mathrm{Fg} \mathrm{CWs}$. A twoway ANOVA showed that the values for the three enzymatic activities were affected by the variables strain and culture medium, and by the combination of both factors. In the presence of $\mathrm{CWs}$ of the pathogen, $\mathrm{SM}+0.5 \% \mathrm{Fg}$-CWs, strain $\mathrm{T} 136$ gave the highest cellulase and chitinase activity values. This result is consistent with its ability to overgrow $F g$ colonies, in comparison with the other three Trichoderma strains that were observed in the 
dual culture assay (Figure 2), and with the high inhibition percentages of the Fg growth obtained in the cellophane membrane assay (Table 2). The lack of cellulase activity that was observed in the supernatants from $\mathrm{SM}+2 \%$ Glu cultures for the four strains shows a catabolite repression of cellulase genes. Although the production of cellulases depends on the microorganism, the carbon and nitrogen sources, and the cultivation conditions, it is well established that the use of glucose as a carbon source leads to a strong repression of cellulase gene transcription by this catabolite [68]. The chitinase activity that was detected in SM $+0.5 \%$ Fg-CWs for T. harzianum T136 could be a consequence of the presence of CWs of the pathogen in the culture medium since chitin is a major component of the $\mathrm{CW}$ of $\mathrm{Fg}$. However, this was not the case for the other three Trichoderma strains.

The beneficial effects of Trichoderma on plants have been reported in terms of growth promotion and defense induction against biotic and abiotic stresses [23,25,69]. Trichoderma can modify the phytohormone signaling networks in plants [70]. Many Trichoderma strains produce IAA, a phytohormone that is crucial in controlling lateral root development and growth [24], as well as the enzyme ACCD, which is able to reduce the ET levels of the plant and as a result promotes growth [31]. Trichoderma spp. can also produce, to a greater or lesser extent, other phytohormones such as ABA, SA, GAs, and CKs [21,29,30,71]. We have previously found that SA production by T. parareesei positively affects its antifungal capacity against Fusarium oxysporum [21]. It may, therefore, be that the greater inhibition of Fg growth that was observed with T. harzianum T136 and T139 could be because they are able to produce more SA. It has been suggested that the production of the CK cZ by Trichoderma may be related to the ability to inhibit the growth of $F g$ [71]. We have also seen that the two strains that produced the $\mathrm{CK} \mathrm{tZ}$ were also the ones that significantly inhibited the growth of $F g$. Greenhouse assays that were performed on Basilio wheat with the four endophytic Trichoderma strains showed that all of them positively affected the plant emergence rate, tillering, and growth under optimal irrigation conditions. The significant differences in plant emergence rates that were observed at six days but not at nine days for the Trichoderma treatments compared to the control may indicate that these endophytic strains positively affect seed germination and plant earliness. Since these four endophytic Trichoderma strains presented ACCD activity and IAA production, their positive effect on wheat growth could be a consequence, at least in part, of these latter traits. In any case, plant growth promotion is not an inherent quality to the genus Trichoderma, as some strains have even been found to cause negative effects [55,72]. We have observed in another study that Trichoderma strains did not promote growth in wheat plants under optimal irrigation conditions, although some of them increased tolerance to drought [30].

In the present work, we also evaluated the effect of the four endophytic Trichoderma strains on wheat plants that were subjected to drought stress through stopping irrigation for 2.5 weeks and maintaining the plants until the crop was harvested. Except for T136 (Table 5), all plants from the other Trichoderma treatments showed, at 40 days, better fresh weight performance compared to the control when they were subjected to water stress. This result is consistent with observations over the long term since plants from the T136 treatment did not differ from the control plants in size and spike weight at 21 weeks (Figure 6). Interestingly, T. harzianum T136 showed the best biocontrol potential against $F g$ and performed worst in supporting plant growth traits under water stress conditions. Our greenhouse trial also showed that the combined application of the four endophytic Trichoderma strains did not improve the results that were achieved with some of the strains applied separately to optimally watered and water-stressed plants.

Plants overproduce ROS when exposed to drought or other environmental stresses. It is well established that plants possess an antioxidant system which involves the action of enzymes such as POD, SOD, and CAT, to reduce the damage that is associated with the overproduction of ROS [40]. It has been also reported that Trichoderma strains protect wheat plants against abiotic stresses by activating the ROS scavenging system $[30,43,44]$. In our study, we observed a higher $\mathrm{H}_{2} \mathrm{O}_{2}$ accumulation in drought-stressed plants, and that accumulation was higher in control plants than in those that were treated with Tricho- 
derma, as previously described [30,73]. The decline in $\mathrm{H}_{2} \mathrm{O}_{2}$ accumulation is not exclusive to environmental stresses, as a decrease in $\mathrm{H}_{2} \mathrm{O}_{2}$ concentration has also been seen in Trichoderma-treated plants compared to those that were infected with fungal pathogens [10]. The levels of $\mathrm{H}_{2} \mathrm{O}_{2}$ were particularly low in water-stressed plants from the T. simmonsii T137 treatment (Figure 5), which also exhibited the highest SOD and POD activity values. Such increased levels of antioxidant activities have also been related to the behavior of tomato plants that were treated with Trichoderma after infection with Fusarium oxysporum f. sp. lycopersici, which is evidence that the maintenance of ROS homeostasis is a general plant defense mechanism that can be induced by Trichoderma [10]. In our study, the highest SOD and POD activity values that were detected in plants treated with T137 were accompanied by the best phenotypic performance of the water-stressed plants in the long term, suggesting that the T137 strain has the ability to help wheat plants overcome drought situations. In this sense, another T. simmonsii strain has been demonstrated to improve soybean seedling growth under conditions of optimal irrigation and drought [74]. The T. simmonsii T137 strain produced the highest amount of ABA and ACCD activity, and, together with T. afroharzianum T138, featured in the maximum IAA output. Previous works that were carried out in wheat have linked Trichoderma ACCD activity to increased plant tolerance to abiotic stresses, such as waterlogging [44] and drought [30]. In plants, ABA is a key phytohormone to regulate adaptation to unfavorable environmental conditions [75]. The ABA that is released by Trichoderma has been related to plant alleviation of salinity [76] and water stress [30]. IAA, in addition to controlling plant growth and root development, can increase plant tolerance to abiotic stresses, acting as a free radical scavenger and thereby overcoming oxidative stress [77]. A previous study has shown that the IAA that is produced by T. longibrachiatum contributed to the IAA concentration in wheat seedling roots under stress conditions [43]. Considering phytohormone production and results that were recorded in plants, T. simmonsii T137 has shown sufficient potential to make it worth assessing its practical applications in real field situations.

\section{Conclusions}

Despite the potential of beneficial fungi in agriculture, their role in the context of water deficits is poorly understood compared to their biocontrol abilities. Overall, this study demonstrated the usefulness of endophytic Trichoderma strains and their positive effects for use in agriculture. However, strain characterization and selection must be undertaken very carefully. The two strains of $T$. harzianum performed best as BCAs against $F g$, but one of them, T. harzianum T136, showed the best fungal CW degrading enzyme activity, yet did not show any ability to protect the wheat plants from drought stress. T. simmonsii T137 was noted to be the best producer of the phytohormones ABA and IAA, and it had the highest ACCD activity. Under water deficit conditions, it was also the best strain to reduce plant-generated oxidative stress and to help wheat plants overcome drought stress.

Supplementary Materials: The following supporting information can be downloaded at: https: / /www.mdpi.com/article/10.3390/jof7121087/s1, Figure S1: Potato dextrose agar (PDA) cultures of the 53 fungal endophytes that were obtained in this study. Table S1: Growth of 54 fungal isolates that were obtained from the root endosphere of wheat Berdun, in potato dextrose broth (PDB) medium with $0,10,20,30$, or $40 \%$ (vol/vol) polyethylene glycol (PEG). The genus was assigned by analyzing the ITS1-ITS4 region sequence.

Author Contributions: R.H. and E.M. conceived this study, designed the experiments, and obtained funding. A.P.-M., H.C.I., T.N., M.I. and M.B.R. performed the experiments. All authors analyzed the data. A.P.-M., E.M. and R.H. wrote the manuscript. All authors have read and agreed to the published version of the manuscript.

Funding: This research is part of the I+D+i project RTI2018-099986-B-I00 funded by the Spanish Government (MCIN/AEI/10.13039/501100011033/FEDER “Una manera de hacer Europa”), and two Regional Government of Castile and Leon projects (SA094P20 and Escalera de Excelencia CLU2018-04) supported by the European Regional Development Fund (FEDER). 
Institutional Review Board Statement: Not applicable.

Informed Consent Statement: Not applicable.

Data Availability Statement: Not applicable.

Acknowledgments: A.P.-M. and M.I. were granted with a predoctoral fellowship of the Regional Government of Castile and Leon.

Conflicts of Interest: The authors declare no conflict of interest.

\section{References}

1. Fontana, D.C.; de Paula, S.; Torres, A.G.; de Souza, V.H.M.; Pascholati, S.F.; Schmidt, D.; Dourado Neto, D. Endophytic fungi: Biological control and induced resistance to phytopathogens and abiotic stresses. Pathogens 2021, 10, 570. [CrossRef] [PubMed]

2. Samolski, I.; Rincón, A.M.; Pinzón, L.M.; Viterbo, A.; Monte, E. The qid74 gene from Trichoderma harzianum has a role in root architecture and plant biofertilization. Microbiology 2012, 158, 129-138. [CrossRef] [PubMed]

3. Carrero-Carrón, I.; Rubio, M.B.; Niño-Sánchez, J.; Navas-Cortés, J.A.; Jiménez-Díaz, R.M.; Monte, E.; Hermosa, R. Interactions between Trichoderma harzianum and defoliating Verticillium dahliae in resistant and susceptible wild olive clones. Plant Pathol. 2018, 67, 1758-1767. [CrossRef]

4. Bae, H.; Sicher, R.C.; Kim, M.S.; Kim, S.-H.; Strem, M.D.; Melnick, R.L.; Bailey, B.A. The beneficial endophyte Trichoderma hamatum isolate DIS 219b promotes growth and delays the onset of the drought response in Theobroma cacao. J. Exp. Bot. 2009, 60, 3279-3295. [CrossRef]

5. Tseng, Y.-H.; Rouina, H.; Groten, K.; Rajani, P.; Furch, A.C.U.; Reichelt, M.; Baldwin, I.T.; Nataraja, K.N.; Shaanker, R.U.; Oelmüller, R. An endophytic Trichoderma strain promotes growth of its hosts and defends against pathogen attack. Front. Plant Sci. 2020, 11, 573670. [CrossRef]

6. Druzhinina, I.S.; Seidl-Seiboth, V.; Herrera-Estrella, A.; Horwitz, B.A.; Kenerley, C.M.; Monte, E.; Mukherjee, P.K.; Zeilinger, S.; Grigoriev, I.V.; Kubicek, C.P. Trichoderma: The genomics of opportunistic success. Nat. Rev. Microbiol. 2011, 9, 749-759. [CrossRef]

7. Cai, F.; Druzhinina, I.S. In honor of John Bissett: Authoritative guidelines on molecular identification of Trichoderma. Fungal Divers 2021, 107, 1-69. [CrossRef]

8. Kaewchai, S.; Soytong, K.; Hyde, K.D. Mycofungicides and fungal biofertilizers. Fungal Divers 2009, 38, 25-50.

9. Nicolás, C.; Hermosa, R.; Rubio, B.; Mukherjee, P.K.; Monte, E. Trichoderma genes in plants for stress tolerance-status and prospects. Plant Sci. 2014, 228, 71-78. [CrossRef]

10. Morán-Diez, M.E.; Martínez de Alba, A.E.; Rubio, M.B.; Hermosa, R.; Monte, E. Trichoderma and the plant heritable priming responses. J. Fungi 2021, 7, 318. [CrossRef]

11. Elad, Y. Biological control of foliar pathogens by means of Trichoderma harzianum and potential modes of action. Crop Prot. 2000, 19, 709-714. [CrossRef]

12. Harman, G.E.; Howell, C.R.; Viterbo, A.; Chet, I.; Lorito, M. Trichoderma species-opportunistic, avirulent plant symbionts. Nat. Rev. Microbiol. 2004, 2, 43-56. [CrossRef]

13. Lorito, M.; Woo, S.L.; Harman, G.E.; Monte, E. Translational research on Trichoderma: From 'omics to the field. Ann. Rev. Phytopathol. 2010, 48, 395-417. [CrossRef] [PubMed]

14. Rivera-Méndez, W.; Obregón, M.; Morán-Diez, M.E.; Hermosa, R.; Monte, E. Trichoderma asperellum biocontrol activity and induction of systemic defenses against Sclerotium cepivorum in onion plants under tropical climate conditions. Biol. Control 2020, 141, 104145. [CrossRef]

15. Kullnig-Gradinger, C.M.; Szakacs, G.; Kubicek, C.P. Phylogeny and evolution of the genus Trichoderma: A multigene approach. Mycol. Rev. 2002, 106, 757-767. [CrossRef]

16. Druzhinina, I.; Kubicek, C.P. Species concepts and biodiversity in Trichoderma and Hypocrea: From aggregate species to species clusters? J. Zhejiang Univ. Sci. B 2005, 6, 100-112. [CrossRef]

17. Hermosa, M.R.; Keck, E.; Chamorro, I.; Rubio, B.; Sanz, L.; Vizcaíno, J.A.; Grondona, I.; Monte, E. Genetic diversity shown in Trichoderma biocontrol isolates. Mycol. Res. 2004, 108, 897-906. [CrossRef]

18. Chaverri, P.; Branco-Rocha, F.; Jaklitsch, W.; Gazis, R.; Degenkolb, T.; Samuels, G.J. Systematics of the Trichoderma harzianum species complex and the re-identification of commercial biocontrol strains. Mycologia 2015, 107, 558-590. [CrossRef]

19. Sanz, L.; Montero, M.; Grondona, I.; Vizcaíno, J.A.; Llobell, A.; Hermosa, R.; Monte, E. Cell wall-degrading isoenzyme profiles of Trichoderma biocontrol strains show correlation with rDNA taxonomical species. Curr. Genet. 2004, 46, 277-286. [CrossRef]

20. Hermosa, R.; Cardoza, R.E.; Rubio, M.B.; Gutiérrez, S.; Monte, E. Secondary metabolism and antimicrobial metabolites of Trichoderma. In Biotechnology and Biology of Biotechnology; Gupta, V.K., Schmoll, M., Herrera-Estrella, A., Druzhinina, I., Upadhyay, R.S., Tuohy, M., Eds.; Elsevier: Amsterdam, The Netherlands, 2014; pp. 125-137.

21. Pérez, E.; Rubio, M.B.; Cardoza, R.E.; Gutiérrez, S.; Bettiol, W.; Monte, E.; Hermosa, R. The importance of chorismate mutase in the biocontrol potential of Trichoderma parareesei. Front. Microbiol. 2015, 6, 1181. [CrossRef]

22. Carrero-Carrón, I.; Trapero-Casas, J.L.; Olivares-García, C.; Monte, E.; Hermosa, R.; Jiménez-Díaz, R.M. Trichoderma asperellum is effective for biocontrol of Verticillium wilt in olive caused by the defoliating pathotype of Verticillium dahliae. Crop Prot. 2016, 88, 45-52. [CrossRef] 
23. Hermosa, R.; Viterbo, A.; Chet, I.; Monte, E. Plant-beneficial effects of Trichoderma and of its genes. Microbiology 2012, 158, 17-25. [CrossRef]

24. Contreras-Cornejo, H.A.; Macías-Rodríguez, L.; Cortés-Penagos, C.; López-Bucio, J. Trichoderma virens, a plant beneficial fungus, enhances biomass production and promotes lateral root growth through an auxin-dependent mechanism in Arabidopsis. Plant Physiol. 2009, 149, 1579-1592. [CrossRef] [PubMed]

25. Rubio, M.B.; Hermosa, R.; Vicente, R.; Gómez-Acosta, F.A.; Morcuende, R.; Monte, E.; Bettiol, W. The combination of Trichoderma harzianum and chemical fertilization leads to the deregulation of phytohormone networking, preventing the adaptative responses of tomato plants to salt stress. Front. Plant Sci. 2017, 8, 294. [CrossRef]

26. Rubio, M.B.; Martínez de Alba, A.E.; Nicolás, C.; Monte, E.; Hermosa, R. Early root transcriptomic changes in wheat seedlings colonized by Trichoderma harzianum under different inorganic nitrogen supplies. Front. Microbiol. 2019, 10, 2444. [CrossRef] [PubMed]

27. Vadassery, J.; Ritter, C.; Venus, Y.; Camehl, I.; Varma, A.; Shahollari, B.; Novák, O.; Strnad, M.; Ludwig-Müller, J.; Oelmüller, R. The role of auxins and cytokinins in the mutualistic interaction between Arabidopsis and Piriformospora indica. Mol. Plant-Microbe Interact. 2008, 21, 1371-1383. [CrossRef] [PubMed]

28. Waqas, M.; Khan, A.L.; Kamran, M.; Hamayun, M.; Khang, S.-M.; Kim, Y.-H.; Lee, I.-J. Endophytic fungi produce gibberellins and indolacetic acid and promotes host-plant growth during stress. Molecules 2012, 17, 10754-10773. [CrossRef] [PubMed]

29. Jaroszuk-Ściseł, J.; Tyśkiewicz, R.; Nowak, A.; Ozimek, E.; Majewska, M.; Hanaka, A.; Tyśkiewicz, K.; Pawlik, A.; Janusz, G. Phytohormones (auxin, gibberellin) and ACC deaminase in vitro synthesized by the mycoparasitic Trichoderma DEMTkZ3A0 strain and changes in the level of auxin and plant resistance markers in wheat seedlings inoculated with this strain conidia. Int. J. Mol. Sci. 2019, 20, 4923. [CrossRef]

30. Illescas, M.; Pedrero-Méndez, A.; Pitorini-Bovolini, M.; Hermosa, R.; Monte, E. Phytohormone production profiles in Trichoderma species and their relationship to wheat plant responses to water stress. Pathogens 2021, 10, 991. [CrossRef]

31. Viterbo, A.; Landau, U.; Kim, S.; Chernin, L.; Chet, I. Characterization of ACC deaminase from the biocontrol and plant growth-promoting agent Trichoderma asperellum T203. FEMS Microbiol. Lett. 2010, 305, 42-48. [CrossRef]

32. Foreign Agricultural Service. U.S. Department of Agriculture (USDA). Available online: https://www.fas.usda.gov/ (accessed on 30 July 2021).

33. Parry, D.W.; Jenkinson, P.; McLeod, L. Fusarium ear blight (scab) in small grain cereals-A review. Plant Pathol. 1995, 44, 207-238. [CrossRef]

34. Pieters, M.N.; Freijer, J.; Baars, B.J.; Fiolet, D.C.M.; van Klaveren, J.; Slob, W. Risk assessment of deoxynivalenol in food: Concentration limits, exposure and effects. Adv. Exp. Med. Biol. 2002, 504, 235-248. [CrossRef]

35. Sarroco, S.; Valenti, F.; Manfredini, S.; Esteban, P.; Bernardi, R.; Puntoni, G.; Baroncelli, R.; Haidukowski, M.; Moretti, A.; Vannaci, G. Is exploitation competition involved in a multitrophic strategy for the biocontrol of fusarium head blight? Pyhtopathology 2019, 109, 560-570. [CrossRef]

36. Kulkarni, M.; Soolanayakanahally, R.; Ogawa, S.; Uga, Y.; Selvaraj, M.G.; Kagale, S. Drought response in wheat: Key genes and regulatory mechanisms controlling root system architecture and transpiration efficiency. Front. Plant Sci. 2017, 5, 106. [CrossRef]

37. Nave, S.; Jacquet, F.; Jeuffroy, M.-H. Why wheat farmers could reduce chemical inputs: Evidence from social, economic, and agronomic analysis. Agron. Sustain. Dev. 2013, 33, 795-807. [CrossRef]

38. Curci, P.L.; Aiese-Cigliano, R.; Zuluaga, D.L.; Janni, M.; Sanseverino, W.; Sonnante, G. Transcriptomic response of durum wheat to nitrogen starvation. Sci. Rep. 2017, 7, 1176. [CrossRef] [PubMed]

39. Illescas, M.; Rubio, M.B.; Hernández-Ruiz, V.; Morán-Diez, M.E.; Martínez de Alba, A.E.; Nicolás, C.; Monte, E.; Hermosa, R. Effect of inorganic $\mathrm{N}$ top dressing and Trichoderma harzianum seed-inoculation on crop yield and the shaping of root microbial communities of wheat plants cultivated under high basal $\mathrm{N}$ fertilization. Front. Plant Sci. 2020, 11, 575861. [CrossRef]

40. Foyer, C.H.; Noctor, G. Oxidant and antioxidant signalling in plants: A re-evaluation of the concept of oxidative stress in physiological context. Plant Cell Environ. 2005, 28, 1056-1071. [CrossRef]

41. Das, K.; Roychoudhury, A. Reactive oxygen species (ROS) and response of antioxidants as ROS-scavengers during environmental stress in plants. Front. Environ. Sci. 2014, 2, 53. [CrossRef]

42. Morán-Diez, M.E.; Cardoza, R.E.; Gutiérrez, S.; Monte, E.; Hermosa, R. TvDim1 of Trichoderma virens is involved in redox-processes and confers resistance to oxidative stresses. Curr. Genet. 2010, 56, 63-73. [CrossRef]

43. Zhang, S.; Gan, Y.; Xu, B. Mechanisms of the IAA and ACC-deaminase producing strain of Trichoderma longibrachiatum T6 in enhancing wheat seedling tolerance to $\mathrm{NaCl}$ stress. BMC Plant Biol. 2019, 19, 22. [CrossRef] [PubMed]

44. Rauf, M.; Awais, M.; Ud-Din, A.; Ali, K.; Gul, H.; Rahman, M.M.; Hamayun, M.; Arif, M. Molecular mechanisms of the 1-aminocyclopropane-1-carboxylic acid (ACC) deaminase producing Trichoderma asperellum MAP1 in enhancing wheat tolerance to waterlogging stress. Front. Plant Sci. 2021, 11, 614971. [CrossRef]

45. Bailey, B.A.; Bae, H.; Strem, M.D.; Roberts, D.P.; Thomas, S.E.; Crozier, J.; Samuels, G.J.; Choi, I.-Y.; Holmes, K.A. Fungal and plant gene expression during the colonization of cacao seedlings by endophytic isolates of four Trichoderma species. Planta 2006, 224, 1449-1464. [CrossRef] [PubMed]

46. Raeder, U.; Broda, P. Rapid preparation of DNA from filamentous fungi. Lett. Appl. Microbiol. 1985, 1, 17-20. [CrossRef]

47. Sadfi-Zouaoui, N.; Hannachi, I.; Rouaissi, M.; Hajlaoui, M.R.; Rubio, M.B.; Monte, E.; Boudabous, A.; Hermosa, M.R. Biodiversity of Trichoderma strains in Tunisia. Can. J. Microbiol. 2009, 55, 154-162. [CrossRef] 
48. Jaklitsch, W.M.; Voglmayr, H. Biodiversity of Trichoderma (Hypocreaceae) in Southern Europe and Macaronesia. Stud. Mycol. 2015, 80,1-87. [CrossRef]

49. Rubio, M.B.; Hermosa, R.; Reino, J.L.; Collado, I.G.; Monte, E. Thetf1 transcription factor of Trichoderma harzianum is involved in 6-pentyl-2H-pyran-2-one production and antifungal activity. Fungal Genet. Biol. 2009, 46, 17-27. [CrossRef]

50. Yedidia, I.; Benhamou, N.; Chet, I. Induction of defense responses in cucumber plants (Cucumis sativus L.) by the biocontrol agent Trichoderma hazrianum. Appl. Environ. Microbiol. 1999, 65, 1061-1070. [CrossRef]

51. Fleet, G.H.; Phaff, H.J. Glucanases in Schizosaccharomyces. Isolation and properties of the cell wall-associated beta-(1,3)-glucanases. J. Biol. Chem. 1974, 249, 1717-1728. [CrossRef]

52. Bradford, M.M. A rapid and sensitive method for the quantitation of microgram quantities of protein utilizing the principle of protein-dye binding. Anal. Biochem. 1976, 72, 248-254. [CrossRef]

53. Montero-Barrientos, M.; Hermosa, R.; Cardoza, R.E.; Gutiérrez, S.; Monte, E. Functional analysis of the Trichoderma harzianum nox1 gene, encoding an NADPH oxidase, relates production of reactive oxygen species to specific biocontrol activity against Pythium ultimum. Appl. Environ. Microbiol. 2011, 77, 3009-3016. [CrossRef] [PubMed]

54. Seo, M.; Jikumaru, Y.; Kamiya, Y. Profiling of hormones and related metabolites in seed dormancy and germination studies. Methods Mol. Biol. 2011, 773, 99-111. [CrossRef]

55. Rubio, M.B.; Domínguez, S.; Monte, E.; Hermosa, R. Comparative study of Trichoderma gene expression in interactions with tomato plants using high-density oligonucleotide microarrays. Microbiology 2012, 158, 119-128. [CrossRef]

56. Morán-Diez, E.; Hermosa, R.; Ambrosino, P.; Cardoza, R.E.; Gutiérrez, S.; Lorito, M.; Monte, E. The ThPG1 endopolygalacturonase is required for the Trichoderma harzianum-plant beneficial interaction. Mol. Plant-Microbe Interact. 2009, 22, 1021-1031. [CrossRef] [PubMed]

57. Elad, Y.; Chet, I.; Henis, Y. A selective medium for improving quantitative isolation of Trichoderma spp. from soil. Phytoparasitica 1981, 9, 59-67. [CrossRef]

58. Velikova, V.; Yordanov, I.; Edreva, A. Oxidative stress and some antioxidants systems in acid rain-treated bean plants. Plant Sci. 2000, 151, 59-66. [CrossRef]

59. Nawaz, A.; Shahbaz, M.; Khan, A.U.; Imran, A.; Marghoob, M.U.; Imtiaz, M.; Mubeen, F. Potential of salt tolerant PGPR in growth and yield augmentation of wheat (Triticum aestivum L.) under saline conditions. Front. Microbiol. 2020, 11, 2019. [CrossRef]

60. de Lamo, F.J.; Takken, F.L.W. Biocontrol by Fusarium oxysporum using endophyte- mediated resistance. Front. Plant Sci. 2020, 11, 37. [CrossRef]

61. Rokni, N.; Alizadeh, H.S.; Bazgir, E.; Darvishnia, M.; Mirzaei-Najafgholi, H. The tripartite consortium of Serendipita indica, Trichoderma simmonsii, and bell pepper (Capsicum annum). Biol. Control 2021, 158, 104608. [CrossRef]

62. Sempere, F.; Santamarina, M.P. Antagonistic interactions between fungal rice pathogen Fusarium verticillioides (Sacc.) Nirenberg and Trichoderma harzianum Rifai. Ann. Microbiol. 2009, 59, 259-266. [CrossRef]

63. Debbi, A.; Boureghda, H.; Monte, E.; Hermosa, R. Distribution and genetic variability of Fusarium oxysporum associated with tomato diseases in Algeria and biocontrol strategy with indigenous Trichoderma spp. Front. Microbiol. 2018, 9, 282. [CrossRef]

64. Taghdi, Y.; Hermosa, R.; Domínguez, S.; Rubio, M.B.; Essalmani, H.; Nicolás, C.; Monte, E. Effectiveness of composts and Trichoderma strains for control of Fusarium wilt of tomato. Phytopathol. Mediterr. 2015, 54, 232-240. [CrossRef]

65. Khruengsai, S.; Pripdeevech, P.; D'Souza, P.E.; Panuwet, P. Biofumigation activities of volatile compounds from two Trichoderma afroharzianum strains against Fusarium infections in fresh chilies. J. Sci. Food Agric. 2021, 101, 5861-5871. [CrossRef] [PubMed]

66. Kredics, L.; Antal, Z.; Szekeres, A.; Hatvani, L.; Manczinger, L.; Vágvölgyi, C.; Erzsébet., N. Extracellular proteases of Trichoderma species. A review. Acta Microbiol. Immunol. Hung. 2005, 52, 169-184. [CrossRef]

67. Schirmböck, M.; Lorito, M.; Wang, Y.L.; Hayes, C.K.; Arisan-Atac, I.; Scala, F.; Harman, G.E.; Kubicek, C.P. Parallel formation and synergism of hydrolytic enzymes and peptaibol antibiotics, molecular mechanisms involved in the antagonistic action of Trichoderma harzianum against phytopathogenic fungi. Appl. Environ. Microbiol. 1994, 60, 4364-4370. [CrossRef]

68. Portnoy, T.; Margeot, A.; Seidl-Seiboth, V.; Le Crom, S.; Chaabane, F.B.; Linke, R.; Seiboth, B.; Kubicek, C.P. Differential regulation of the cellulase transcription factors XYR1, ACE2, and ACE1 in Trichoderma reesei strains producing high and low levels of cellulase. Eukaryot. Cell 2011, 10, 262-271. [CrossRef]

69. Mastouri, F.; Björkman, T.; Harman, G.E. Seed treatment with Trichoderma harzianum alleviates biotic, abiotic, and physiological stresses in germinating seeds and seedlings. Phytopathology 2010, 100, 1213-1221. [CrossRef]

70. Hermosa, R.; Rubio, M.B.; Cardoza, R.E.; Nicolás, C.; Monte, E.; Gutiérrez, S. The contribution of Trichoderma to balancing the costs of plant growth and defense. Int. Microbiol. 2013, 16, 69-80. [PubMed]

71. Bean, K.M.; Kisiala, A.B.; Morrison, E.N.; Emery, R.J.N. Trichoderma synthesizes cytokinins and alters cytokinin dynamics of inoculated Arabidopsis seedlings. J. Plant Growth Regul. 2021, 1-17. [CrossRef]

72. Schweiger, R.; Padilla-Arizmendi, F.; Nogueira-López, G.; Rostás, M.; Lawry, R.; Brown, C.; Hampton, J.; Steyaert, J.M.; Müller, C.; Mendoza-Mendoza, A. Insights into metabolic changes caused by the Trichoderma virens-maize root interaction. Mol. Plant-Microbe Interact. 2021, 34, 524-537. [CrossRef] [PubMed]

73. Mastouri, F.; Björkman, T.; Harman, G.E. Trichoderma harzianum enhances antioxidant defense of tomato seedlings and resistance to water deficit. Mol. Plant-Microbe Interact. 2012, 25, 1264-1271. [CrossRef] [PubMed] 
74. Bakhshandeh, E.; Gholamhosseini, M.; Yaghoubian, Y.; Pirdashti, H. Plant growth promoting microorganisms can improve germination, seedling growth and potassium uptake of soybean under drought and salt stress. Plant Growth Regul. 2020, 90, 123-136. [CrossRef]

75. Zhu, J.K. Salt and drought stress signal transduction in plants. Annu. Rev. Plant Biol. 2002, 53, 247-273. [CrossRef] [PubMed]

76. Zhao, L.; Zhang, Y. Effects of phosphate solubilization and phytohormone production of Trichoderma asperellum Q1 on promoting cucumber growth under salt stress. J. Integr. Agric. 2015, 14, 1588-1597. [CrossRef]

77. Siddiqui, M.H.; Alamri, S.A.; Al-Khaishany, M.Y.Y.; Al-Qutami, M.A.; Ali, H.M.; Khan, M.N. Sodium nitroprusside and indole acetic acid improve the tolerance of tomato plants to heat stress by protecting against DNA damage. J. Plant Interact. 2017, 12, 177-186. [CrossRef] 